Working Paper/Document de travail

2007-46

\title{
Endogenously Segmented Asset Market in an Inventory Theoretic Model of Money Demand
}

by Jonathan Chiu 
Bank of Canada Working Paper 2007-46

August 2007

\title{
Endogenously Segmented Asset Market in an Inventory Theoretic Model of Money Demand
}

\author{
by \\ Jonathan Chiu \\ Monetary and Financial Analysis Department \\ Bank of Canada \\ Ottawa, Ontario, Canada K1A OG9 \\ jchiu@bankofcanada.ca
}

Bank of Canada working papers are theoretical or empirical works-in-progress on subjects in economics and finance. The views expressed in this paper are those of the author.

No responsibility for them should be attributed to the Bank of Canada. 


\section{Acknowledgements}

This is a chapter of my dissertation. I would like to thank my advisors Igor Livshits and Miguel Molico for their invaluable guidance. I am also grateful to Ian Christensen, Chris Edmond, Andrés Erosa, Huberto Ennis, Joel Fried, David Laidler, Jim MacGee, Iourii Manovskii, Cesaire Meh, Maxim Poletaev, Malik Shukayev, Alex Wolman, Randall Wright as well as seminar participants in the CEA 2004 Annual Meeting, SED 2005 Meeting, the Bank of

Canada, Federal Reserve Bank of Cleveland, Federal Reserve Bank of Kansas City, Federal Reserve Bank of Richmond, the University of Concordia, McMaster, Pennsylvania, Simon Fraser and Western Ontario for helpful comments and suggestions. 


\begin{abstract}
This paper studies the effects of monetary policy in an inventory theoretic model of money demand. In this model, agents keep inventories of money, despite the fact that money is dominated in rate of return by interest bearing assets, because they must pay a fixed cost to transfer funds between the asset market and the goods market. Unlike the exogenous segmentation models in the literature, the timings of money transfers are endogenous. By allowing agents to choose the timings of money transfers, the model endogenizes the degree of market segmentation as well as the magnitude of liquidity effects, price sluggishness and variability of velocity. First, I show that the endogenous segmentation model can generate the positive long run relationship between money growth and velocity in the data which the exogenous segmentation model fails to capture. Second, I show that the short run effects of money shocks in an exogenous segmentation model (such as the linear inflation response to money shock, the liquidity effect and the sluggish price adjustment) are not robust. In an endogenous segmentation model, the equilibrium response to money shocks is non-linear and non-monotonic. Moreover, for large money shocks, there is no liquidity effect and no sluggish price adjustment.

JEL classification: E31, E41, E50

Bank classification: Transmission of monetary policy; Monetary policy framework
\end{abstract}

\title{
Résumé
}

L'auteur examine les effets de la politique monétaire à l'aide d'un modèle de demande de monnaie inspiré de la théorie de la gestion des stocks. Même si les actifs rémunérés offrent un meilleur taux de rendement que la monnaie, les agents conservent des stocks de monnaie, car les transferts de fonds entre marché financier et marché des biens sont soumis à un coût fixe. Prenant le contrepied des modèles avec segmentation exogène présentés dans la littérature, l'auteur permet aux agents de décider eux-mêmes du moment des transferts. Il fait ainsi du degré de segmentation des marchés une donnée endogène de son modèle, au même titre que l'ampleur des effets de liquidité, la lenteur de l'ajustement des prix et la variabilité de la vitesse de circulation de la monnaie. L'auteur montre d'abord que, contrairement au modèle avec segmentation exogène, son modèle avec segmentation endogène parvient à reproduire la relation positive qui lie à long terme la croissance et la vitesse de circulation de la monnaie d'après les données. Il montre ensuite que les répercussions (réaction linéaire de l'inflation, effet de liquidité, rigidité dans l'ajustement des prix) entraînées à court terme par les chocs monétaires dans les modèles avec segmentation exogène ne sont pas robustes. Dans le modèle avec segmentation endogène, les 
valeurs d'équilibre réagissent aux chocs monétaires de façon non linéaire et non monotone. De plus, lorsque ces chocs sont importants, on n'observe aucun effet de liquidité et les prix s'ajustent rapidement.

Classification JEL : E31, E41, E50

Classification de la Banque : Transmission de la politique monétaire; Cadre de la politique monétaire 


\section{Introduction}

An important characteristic for a good monetary model to have is the ability to reproduce the real world's response to monetary policy. Many economists agree, for instance, that empirical evidence supports the presence of liquidity effects, sluggish price adjustment and the variability of the velocity of money ${ }^{1}$. The liquidity effect is viewed as an important channel through which the monetary policy has impact on the economy. And the magnitude of the policy impact on nominal output, as suggested by the equation of exchange, depends on the velocity of money. If the price level cannot adjust fully, then the short run real output has to be affected. Therefore, responses of the interest rate, price level and velocity play critical roles in determining the short run real effects of monetary policy. Standard monetary models, however, have difficulties generating these features. For example, in a standard cash-in-advance (CIA) model, a temporary money shock results in an immediate and full adjustment of price level, without any effect on the interest rate or the velocity of money ${ }^{2}$. The key reason is that agents in a CIA model are allowed to transfer money from an asset market to the goods market costlessly every period ${ }^{3}$.

Some economists have argued that introducing frictions into the asset market can improve the performance of the standard model (See Baumol (1952), Tobin (1956), Lucas (1990) and Alvarez, Atkeson and Kehoe (1999)). In this paper, I build on this literature to endogenize agents' decision on money transfers between the goods market and the asset market by assuming that agents must pay a fixed transaction cost to transfer money. In my model, the optimal timing of money transfers is determined by the trade-off between the transaction cost and the interest forgone by holding money. Because of the fixed cost, agents may choose to keep inventories of money instead of making transfers every period. As a result, the asset market is segmented in the sense that when the government injects money, only a fraction of

\footnotetext{
${ }^{1}$ Liquidity effects refer to the drop in short-term interest rates in response to money injections. See Cochrane (1989), Christiano, Eichenbaum and Evans (1995, 1997), Strongin (1992), Gordon and Leeper (1994) and Hamilton (1997) for empirical support. Price sluggishness refers to the slow response of the price level to money shocks. See, for example, Christiano, Eichenbaum and Evans (1997, 2001). Variability of velocity refers to the long-run and short-run fluctuations of the income velocity of money. See Hodrick, Kocherlakota and Lucas (1991) and Wang and Shi (2001).

${ }^{2}$ While a limited participation model can produce liquidity effects, it cannot match the degree of the price sluggishness and the variability of velocity. Also, a standard sticky price model is able to generate price sluggishness but it has difficulty matching the magnitudes of the other two features. See, for example, Christiano (1991), Christiano, Eichenbaum and Evans (1997), Edge (2000), Keen (2001) and Dotsey and King (2001).

${ }^{3}$ When money is injected into the asset market, all agents are on the demand side of the transaction. They just increase their cash holdings in equal proportion to the money shock, without affecting the equilibrium interest rate. Because agents spend all of their cash holdings in the goods market immediately, there is a proportional jump in the current price level and the velocity of money is identically equal to 1.
} 
agents, currently in contact with the asset market, are on the other side of the transaction. Therefore, the interest rate must decline to induce these agents to absorb a disproportionate share of the new money, leading to the liquidity effect. Because the new money is then kept as an inventory by this fraction of agents and is spent gradually over several periods' time, the price level rises gradually through time, even though prices are completely flexible, resulting in the sluggish price response. Also, the money injection can change the distribution of money shares across agents, leading to the variability of the velocity. Moreover, by endogenizing the degree of market segmentation, the model also endogenizes the degree of price sluggishness, the fluctuation of velocity and the magnitude of liquidity effects. I refer this model as an inventory model of money demand with endogenous segmentation.

Alvarez, Atkeson and Edmond (2003) study a simplified version of the framework discussed above, which I refer as an inventory model with exogenous segmentation. Their exogenous segmentation model can also generate the liquidity effect, the price sluggishness and the variability of velocity. But, instead of endogenizing the timing of money transfers, their model exogenously imposes a restriction that agents must make transfers once every $N>1$ periods, where $N$ is taken as a parameter. Under this restriction, agents are not allowed to adjust the timing of transfers in response to policy interventions, even in extreme changes of circumstance. As suggested by Lucas's critique, the validity of their model implications is questionable because private agents' choice of money transfer timing is taken as a structural parameter invariant under interventions. In particular, one would expect that, if agents are allowed to adjust their transfer timings, a money injection may induce more agents to make money transfers in the current period, and thus dampen the liquidity effect. Moreover, a sufficiently large inflation may cause agents to increase their transfer frequencies, and thus speeding up the price adjustment process.

The main objective of this paper is to derive long run and short run effects of monetary policy in an endogenous segmentation model and contrast its implications with that in an exogenous segmentation model. For a small money shock, agents do not adjust their transfer frequencies and thus the two models produce the same implications. For a large money shock, however, it is optimal for agents to adjust their transfer frequencies and thus the implications of two models differ.

My key findings are as follows. I show that the endogenous-segmentation model can generate the positive long run relationship between money growth and velocity in the data which the exogenous segmentation model fails to capture. In an exogenous segmentation model, the long run velocity of money is decreasing in money growth. In an endogenous 
segmentation model, there are discrete jumps in the long run velocity as money growth rate rises. I also study the short run effects of money shocks. First, in an exogenous segmentation model, responses to money shocks are linear, monotonic and symmetric. By contrast, in an endogenous segmentation model, responses are non-linear, non-monotonic and asymmetric. Second, an exogenous segmentation model is a good approximation of the endogenous segmentation model only for small money shocks. For large money shocks, implications of the exogenous segmentation model are not robust.

This paper is related to the existing literature of inventory theoretic models of money demand. These models are first studied by Baumol (1952) and Tobin (1956) who consider the optimal cash management of an individual agent. Jovanovic (1982), Romer (1986) and Chatterjee and Corbae (1992) develop general equilibrium versions of these models and use them to study how different constant inflation rates affect the steady state. All of those models, however, cannot examine the dynamic response to money shocks and thus cannot study such issues as the sluggishness of the price adjustment and the presence of the liquidity effect. While Grossman and Weiss (1983), Rotemberg (1984) and Alvarez, Atkeson and Edmond (2003) study the effect of monetary policy in the transition, they consider exogenous segmentation models and thus agents are not allowed to adjust their transfer frequencies in response to policy shocks. ${ }^{4}$ In the model by Alvarez, Atkeson and Kehoe (1999), agents also have to pay a fixed cost to trade asset. However, they assume that the CIA constraint is always binding and thus agents do not keep inventories of money. A closely related and perhaps complementary work to this paper is Kahn and Thomas (2006) who study a similar inventory problem in a different model setup. ${ }^{5}$ They do not look at the long run effects of money growth, or the non-linear and asymmetric short run responses to money shocks which are the main contributions of this paper.

The remainder of this paper is organized as follows. In section 2, I outline the model setup. In Section 3, I present properties of the stationary equilibrium in the exogenous segmentation and endogenous segmentation models. Section 4 discusses the long-run relationship between the velocity of money and the money growth. Section 5 derives short-run responses of the economy to money policy shocks. Section 6 concludes this paper.

\footnotetext{
${ }^{4}$ Grossman(1987) studies a Baumol-Tobin model with proportional transaction costs in which the money transfer timing is partly endogenous.

${ }^{5}$ Kahn and Thomas assume complete market and idiosyncratic fixed costs to gain tractability. Here, I assume a constant fixed cost and allow only nominal bonds to highlight the distribution effect of money shock. Also, I focus on characterizing the full dynamic path after a one time shock.
} 
Sub-period 1

$\mathrm{t}$

Asset Market
Sub-period 2

Consumption Good

Market $t+1$
- revenue $\mathrm{P}_{\mathrm{t}-1}$ deposit to

brokerage account

- open market operation

- money transfer

- trade bond

Figure 1: Time line

\section{Model}

Consider a cash-in-advance economy with an asset market and a goods market. Time is discrete and denoted $t=0,1,2, \ldots$. There is a measure one of households. Each household comprises of a seller and a buyer. We assume that each household $i \in[0,1]$ has access to two financial accounts: the brokerage account manages its portfolio of assets and the checking account manages its money balance held for transactions in the goods market. There is a government that injects money into the asset market via open market operations. The supply of money stock in period $t$ is $M_{t}$ and the (gross) growth rate is $\mu_{t}=M_{t} / M_{t-1}$.

Households that participate in the open market operation purchase money with assets held in their brokerage accounts. These households must transfer money to their checking account before they can spend it on consumption. To make a transfer of money, a household needs to pay a fixed utility cost $\eta_{t}>0{ }^{6}$. Each household receives one unit of endowment of consumption good at the beginning of each period and the preference of household $i$ is represented by

$$
\sum_{t=0}^{\infty} \beta^{t}\left[\log c_{t}(i)-\eta_{t} J\left(x_{t}(i)\right)\right], \quad 0<\beta<1
$$

In $(1), c_{t}(i)$ and $x_{t}(i)$ denote respectively the real amount of consumption and money transfer of $i$ in period $t . J(x)$ is an indicator function such that $J(x)=1$ when $x \neq 0$ and $J(x)=0$ when $x=0$. Households cannot consume their own endowment, and have to purchase

\footnotetext{
${ }^{6}$ Measuring the fixed cost in terms of utility allows for a direct comparison with the existing exogenous segmentation models in which no goods are lost as a result of money transfers. Here, the fixed cost captures the time cost, decision making and intermediation costs associated with money transfers and portfolio adjustment.
} 
consumption from other households in the goods market. The timing of the model is as follows. Each period is divided into two sub-periods (Figure 1). In the first sub-period, each household trades assets held in its brokerage account in the asset market. In the second sub-period, the buyer in each household purchases consumption in the goods market using money held in the checking account, while the seller exchanges the endowment in the goods market for $P_{t}$ amount of money which denotes the price level in the current period. In the next period, the revenue is deposited into the household's brokerage account in the asset market.

We turn now our attention to the technology of transferring balances between the brokerage and the checking accounts. There are two special cases. First, when the transfer timing is exogenous, each household can only make transfers once every $N$ periods where $N$ is a parameter, irrespective of the state of the economy. If $N=1$, it reduces to the standard cash-in-advance model. Second, when the transfer timing is endogenous, all households can make transfers in the current period after paying a fixed cost. One would choose to make a transfer when the benefits of doing so outweigh the associated fixed cost and thus the transfer decision depends on the condition of the economy. These special cases may be represented by the following two specifications of the fixed cost. Suppose a household is allowed to make a money transfer in period $t$ after paying a fixed utility cost $\eta_{t}$. If the transfer timing is exogenous with a transfer opportunity once every $N$ periods, then the fixed cost paid by a type $j \in\{0,1, \ldots, N-1\}$ household is given by

$$
\eta_{j+s}\left\{\begin{array}{l}
=0, \text { for } s=0, N, 2 N, \ldots \\
=\infty, \text { otherwise }
\end{array}\right.
$$

When the transfer timing is endogenous, I assume that $\eta_{t}=\eta>0$ for all $t$.

The money holding of household $i$ at the beginning of the second sub-period is denoted $M_{t}(i)$ which is equal to the quantity of money that it held over in its checking account last period $Z_{t-1}(i)$ as well as the transfer $P_{t} x_{t}(i)$ made this period. The household spends part of $M_{t}(i)$ on goods, $P_{t} c_{t}(i)$, and carries the unspent balance in its checking account into next period, $Z_{t}(i) \geq 0$. In sum: 


$$
\begin{aligned}
& M_{t}(i)=Z_{t-1}(i)+P_{t} x_{t}(i), \\
& M_{t}(i) \geq P_{t} c_{t}(i)+Z_{t}(i)
\end{aligned}
$$

In addition to the constraints on the household's checking account, the household also faces a sequence of constraints on its brokerage account. I assume that, in the asset market, the household can trade one-period bonds, each of which pays one dollar into the household's brokerage account next period. Let $B_{t}(i)$ denote the stock of bonds held by household $i$ at the end of period $t$. I assume that each household's real bond holdings must remain within an arbitrarily large bound. A household's bond and money holdings in its brokerage account must satisfy:

$$
B_{t-1}(i)+P_{t-1}-P_{t} \tau_{t}=q_{t} B_{t}(i)+P_{t} x_{t}(i),
$$

where $q_{t}$ is the price of bond in period $t$ and $P_{t} \tau_{t}$ are nominal lump-sum taxes. Each household maximizes (1) subject to (2),(3) and (4).

Let $\bar{B}_{t}$ be the total stock of government bonds in period $t$. The government faces a sequence of budget constraints

$$
\bar{B}_{t-1}=M_{t}-M_{t-1}+P_{t} \tau_{t}+q_{t} \bar{B}_{t}
$$

together with an arbitrarily large bound on the government's real bond issuance. The government implements monetary policy by open market operations in the asset market. In particular, the government increases the supply of money stock by buying bonds with money, and reduces the money stock by selling bonds for money. The market clearing conditions are given by:

$$
\begin{aligned}
\int_{0}^{1} c_{t}(i) d i & =1 \\
\int_{0}^{1} M_{t}(i) d i & =M_{t} \\
\int_{0}^{1} B_{t}(i) d i & =\bar{B}_{t}
\end{aligned}
$$


An equilibrium of this economy is a collection of prices $\left\{q_{t}, P_{t}\right\}_{t=0}^{\infty}$, household decision $\left\{c_{t}(i), x_{t}(i), B_{t}(i), M_{t}(i), Z_{t}(i)\right\}_{t=0}^{\infty}$, and a government policy $\left\{\tau_{t}, \mu_{t}, \bar{B}_{t}\right\}_{t=0}^{\infty}$, such that (i) the household decision solves its problem when prices are taken as given, (ii) the government budget constraint, and (iii) the goods market, money market, and the bond market clearing conditions are satisfied for all $t$.

\section{Stationary Equilibrium}

This section derives the properties of the stationary equilibrium. I first examine the benchmark case with exogenous transfer timing and then move to the case with endogenous transfer timing. I assume that the gross money growth rate is constant at $M_{t} / M_{t-1}=\mu_{s s}$ and the tax rate is constant at $\tau$. Let us scale the nominal variables by the aggregate money stock and define $\bar{b}_{t}=\bar{B}_{t} / M_{t}, b_{t}(i)=B_{t}(i) / M_{t}, z_{t}(i)=Z_{t}(i) / M_{t}$, and $p_{t}=P_{t} / M_{t}$.

\subsection{Exogenous-Segmentation Model}

In the exogenous segmentation model, each household is allowed to make a transfer once every $N$ periods. In each period, there are $N$ types of households $(s=0,1,2, \ldots, N-1$ where $s$ is the number of time periods since a household last withdrew from the brokerage account) and each type is of measure $\frac{1}{N}$. I aim to derive a stationary equilibrium with constant prices $(p, q)$. To derive the equilibrium, I need to choose an initial distribution of bond holdings which will give rise to a constant bond price $q=\frac{\beta}{\mu_{s s}} .{ }^{7}$ As shown in the Appendix, the first order conditions of households imply that the consumption and money holdings of a type $j$ agent is given by

$$
\begin{aligned}
c_{j} & =\frac{\beta^{j}(1-\beta)}{\mu_{s s}^{j}\left(1-\beta^{N}\right)} x \\
z_{j} & =\frac{\beta^{j+1}\left(1-\beta^{N-j-1}\right)}{1-\beta^{N}} \frac{x p}{\mu_{s s}^{j}}, j=0,1, \ldots, N-1
\end{aligned}
$$

Note that after a type 0 household replenishes its checking account, its money holding, $z_{s}$, is decreasing over time until it is exhausted in $N$ periods' time. Due to discounting and inflation, the amount of consumption, $c_{s}$, is decreasing over time (by a factor $\frac{\beta}{\mu_{s s}}$ ) until the

\footnotetext{
${ }^{7}$ I focus on equilibria in which no households hold money in the brokerage accounts, and households exhaust their money holding before making transfers. See the Appendix for the details.
} 
next withdrawal. The goods market and the money market equilibrium conditions imply

$$
\begin{aligned}
& x=N \frac{1-\beta^{N}}{1-\beta}\left(\frac{1-\beta / \mu_{s s}}{1-\beta^{N} / \mu_{s s}^{N}}\right) \\
& p=\left(\sum_{s=0}^{N-1} \frac{1}{\mu_{s s}^{s}} \frac{\beta^{s}\left(1-\beta^{N-s}\right)}{1-\beta}\right)^{-1} \frac{1-\beta^{N} / \mu_{s s}^{N}}{1-\beta / \mu_{s s}},
\end{aligned}
$$

In a standard cash-in-advance model, $N=1$, and all of the money stock is circulated every period, accordingly the price level is one. Finally, it can be shown that the bond holdings are given by

$$
\left(\begin{array}{c}
b_{0} \\
\vdots \\
\vdots \\
\vdots \\
b_{N-1}
\end{array}\right)=\left(\begin{array}{ccccc}
-\mu_{s s} q & 0 & \ldots & 0 & 1 \\
1 & -\mu_{s s} q & 0 & \cdots & 0 \\
0 & 1 & -\mu_{s s} q & \ddots & 0 \\
\vdots & \ddots & \ddots & \ddots & 0 \\
0 & 0 & 0 & 1 & -\mu_{s s} q
\end{array}\right)^{-1}\left(\begin{array}{c}
p x \mu_{s s}+p \mu_{s s} \tau-p \\
p \mu_{s s} \tau-p \\
\vdots \\
\vdots \\
p \mu_{s s} \tau-p
\end{array}\right)
$$

\subsection{Endogenous-Segmentation Model}

In the endogenous segmentation model, all households can choose to make transfers in response to the condition of the economy. Given $\left(z_{-1}, b_{-1}, p_{-1}\right)$, a household chooses sequences of consumption, transfer, bond and money holding to maximize

$$
\begin{gathered}
\sum_{t=0}^{\infty} \beta^{t}\left[\log c_{t}-J\left(x_{t}\right) \eta\right] \\
\text { s.t. } \quad b_{t}=\frac{1}{q_{t}}\left[\left(b_{t-1}+p_{t-1}\right) / \mu_{s s}-p_{t}\left(\tau+x_{t}\right)\right] \\
z_{t}=z_{t-1} / \mu_{s s}+p_{t}\left(x_{t}-c_{t}\right) \\
J(x)=\left\{\begin{array}{lll}
0 & \text { if } x=0 \\
1 & \text { if } x \neq 0
\end{array}\right.
\end{gathered}
$$


I first consider the decision of a household with $z_{-1}=0$ and show that, with constant prices, it is optimal to choose equally spaced transfers. Let $d^{*}=\left(0, t_{1}^{*}, t_{2}^{*}, \ldots\right)$ denote the optimal choice of transfer dates. It is shown in the Appendix that, if $p_{t}=p$ and $q_{t}=q=\frac{\beta}{\mu_{s s}}$ for all $t$, then $t_{j+1}^{*}-t_{j}^{*}=t_{1}^{*}=n$ for $j=1,2, \ldots$ and for some positive integer $n .{ }^{8}$

How should this household choose the optimal $n$ ? Increasing $n$ makes the payment of the transfer cost less frequent but also makes the consumption profile less smooth. This tradeoff is illustrated by the two functions $G(n)$ and $D(n)$ in Figure 2 (derived in the Appendix). $D(n)=\ln \left(\frac{\beta}{\mu_{s s}}\right)\left(1-\beta^{n}+n \ln \beta\right)$ represents the marginal utility cost of increasing $n$ due to the unsmoothed consumption profile. $G(n)=-\eta(1-\beta) \ln \beta$ represents the marginal utility gain of increasing $n$ due to less frequent payment of transfer cost.

Figure 2: Determination of optimal $n$

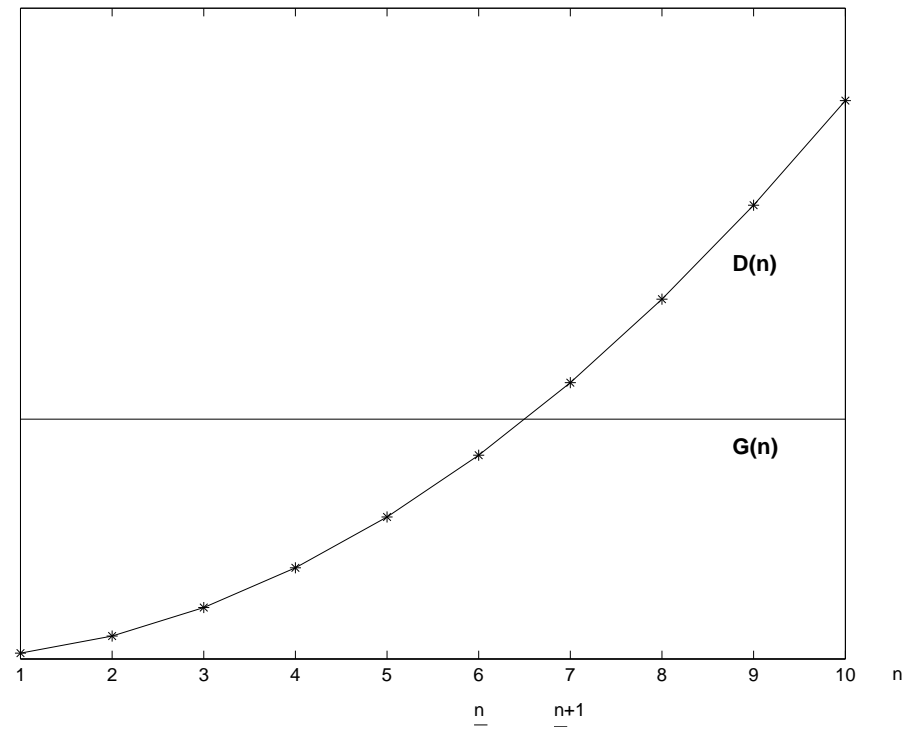

Because $G(n)>0, D(0)=0, D(\infty)=\infty, D^{\prime}(n)>0$ and $D^{\prime \prime}(n)>0$, we can define a unique $\widehat{n}$ that solves $D(\widehat{n})=G(\widehat{n})$. Denote the value of choosing $n$ by $V(n)$. When $n<\widehat{n}, V(n)$ is increasing in $n$ because the marginal gain from the transfer cost reduction can compensate for the marginal cost of having a unsmoothed consumption profile. When $n>\widehat{n}, V(n)$ is decreasing in $n$ because the marginal cost of a unsmoothed consumption profile outweighs the marginal gain from saving the transfer cost. Define $\underline{n}$ as the integer part of $\widehat{n}$ so that $\underline{n} \leq \widehat{n}<\underline{n}+1$. The optimal choice of $n$, denoted as $n^{*}$, is given by

\footnotetext{
${ }^{8}$ Similar results can be found in continuous time inventory theoretic models such as Tobin (1956) and Romer(1986).
} 


$$
n^{*}=\left\{\begin{array}{c}
\underline{n} \text { if } V(\underline{n}) \geq V(\underline{n}+1) \\
\underline{n}+1 \text { if } V(\underline{n}+1) \geq V(\underline{n})
\end{array}\right.
$$

After solving the individual problem, we can now turn to derive properties of the symmetric stationary equilibrium (SSE). In what follows, we focus on equilibria in which the initial endowments of bonds are such that the fraction of households making money transfers is constant over time. Moreover, the initial bond holding is such that households that make transfers at the same period start with identical initial wealth. It is shown in the Appendix that, for each set of $\left(\eta, \beta, \mu_{s s}, \tau\right)$, a SSE exists, and generically, this is the unique SSE.

Figure 3: A symmetric stationary Equilibrium

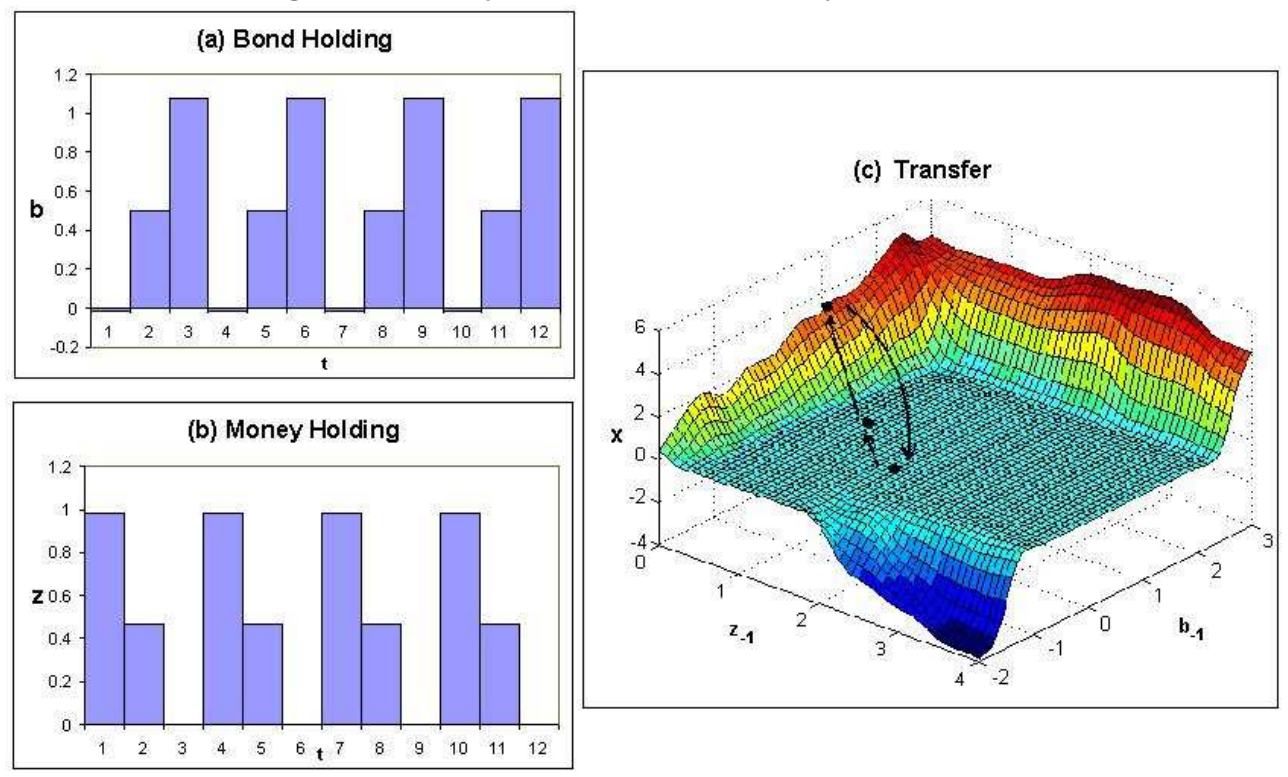

As an example, Figure 3 shows the cycles of money and bond holdings as well as the optimal transfer as a function of the money and bond holdings, $x\left(z_{-1}, b_{-1}\right)$, in a SSE with $\left(\eta, \beta, \mu_{s s}, \tau\right)=(0.5,0.9,1,0.1)$. In this equilibrium, a household chooses to withdraw once every three periods. Graph (c) shows that, when $z_{-1}$ is low and/or $b_{-1}$ is high, the household tends to withdraw from the brokerage account. When $z_{-1}$ is high and $b_{-1}$ is low, it tends to deposit to the brokerage account. In all other cases, it chooses not to transfer.

A distinct feature of an endogenous segmentation model is that $N=n$ responds to changes in the state of the economy. How is the equilibrium value of $N$ affected by the sizes of the fixed cost and money growth? Note that an increase in $\eta$ shifts $G(n)$ upward and leaves $D(n)$ unchanged. An increase in $\mu_{s s}$ shifts $D(n)$ upward and leaves $G(n)$ unchanged. 
Therefore, the equilibrium value of $N$ is increasing in $\eta$ and decreasing in $\mu_{s s}{ }^{9}$. The intuition is that the net gain from making a transfer is increasing in the inflation rate and is decreasing in the fixed cost. Figure 4 plots the equilibrium choice of $N$ for different combinations of $\eta$ and $\mu_{s s}$, when $\beta=0.9$. Note that, when $\eta=0$, the model degenerates to the standard cash-in-advance model in which households make transfer every period $(N=1)$.

Figure 4: Endogenous Choice of $N(\beta=0.9)$

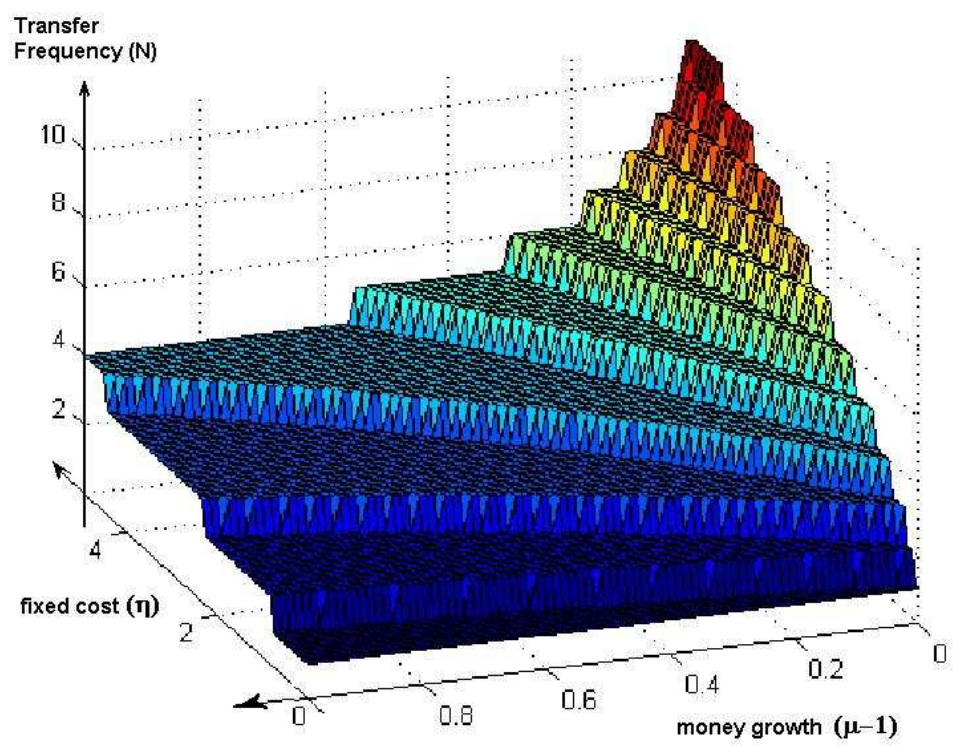

\section{Velocity and Money Growth in the Long Run}

This section discusses the long-run relationships between the velocity and the money growth rate in the exogenous segmentation model and the endogenous segmentation model. I will argue that the implication of the endogenous segmentation model is more consistent with the data.

\subsection{Exogenous-Segmentation Model}

In the exogenous segmentation model, it can be shown that the aggregate velocity of the economy in a stationary equilibrium is given by

\footnotetext{
${ }^{9}$ Jovanovic(1982) and Romer(1986) consider continuous time models in settings different from this paper and derive similar conclusions.
} 


$$
\bar{v}=\left(\sum_{j=0}^{N-1} \frac{1}{\mu_{s s}^{j}} \frac{\beta^{j}\left(1-\beta^{N-j}\right)}{1-\beta}\right)^{-1} \frac{1-\beta^{N} / \mu_{s s}^{N}}{1-\beta / \mu_{s s}}
$$

and, as $\beta \rightarrow 1$, it becomes

$$
\bar{v}=\left[\sum_{j=0}^{N-1} \frac{N-j}{\mu_{s s}^{j}}\right]^{-1} \frac{\mu_{s s}^{N}-1}{\mu_{s s}^{N-1}\left(\mu_{s s}-1\right)}
$$

Note that, when $N=1$, the model reduces to the standard cash-in-advance model and the velocity is constant at one. The following proposition concerns the effect of the money growth when $N>1$ :

Proposition 1: In an exogenous-timing model, if $N>1$ and $\mu_{s} s>1$, as $\beta \rightarrow 1, \bar{v}$ is decreasing in $\mu_{s s} \cdot{ }^{10}$

An easy way to get intuition for this proposition is to consider the simple case when $N=2$. With $\log$ utility and $\beta \rightarrow 1$, a type $s=0$ household (who just made a transfer) with money holding $M_{t}(0)$ spends $P_{t} c_{t}(0)=\frac{1}{2} M_{t}(0)$ on current consumption and keeps $M_{t+1}(1)=\frac{1}{2} M_{t}(0)$ money holding for the next period. With an inflation rate $\mu_{s s}$, the current money holdings of the two types are related by $M_{t}(1)=\frac{1}{2 \mu_{s s}} M_{t}(0)$. The money market clearing condition $M_{t}=\frac{1}{2} M_{t}(0)+\frac{1}{2} M_{t}(1)$ then implies that the shares of money holding are $\frac{M_{t}(0)}{M_{t}}=\frac{4 \mu_{s s}}{2 \mu_{s s}+1}$ and $\frac{M_{t}(1)}{M_{t}}=\frac{2}{2 \mu_{s s}+1}$. Moreover, denoting $\bar{v}_{t}$ as the aggregate velocity and $v_{t}(i)$ as the individual velocity of type $i$ in period $t$, we can show that $\bar{v}_{t}$ is given by

$$
\begin{aligned}
\bar{v}_{t} & =\frac{1}{2} \frac{P_{t} c_{t}(0)}{M_{t}}+\frac{1}{2} \frac{P_{t} c_{t}(1)}{M_{t}} \\
& =\frac{1}{2}\left(v_{t}(0)\right)\left(\frac{M_{t}(0)}{M_{t}}\right)+\frac{1}{2}\left(v_{t}(1)\right)\left(\frac{M_{t}(1)}{M_{t}}\right) \\
& =\frac{\mu_{s s}+1}{2 \mu_{s s}+1}
\end{aligned}
$$

Therefore, the velocity is decreasing in money growth rate: $\frac{d \bar{v}}{d \mu_{s s}}=-\frac{1}{\left(2 \mu_{s s}+1\right)^{2}}<0$. The

\footnotetext{
${ }^{10}$ For $\beta<1$, simulation shows that $\bar{v}$ is still decreasing in $\mu_{s s}$ for reasonable sizes of $\beta$ and $N$. It holds for example for $\beta>0.3$ and $N<20$.
} 
Figure 5: Velocity and Money Growth in the Long Run

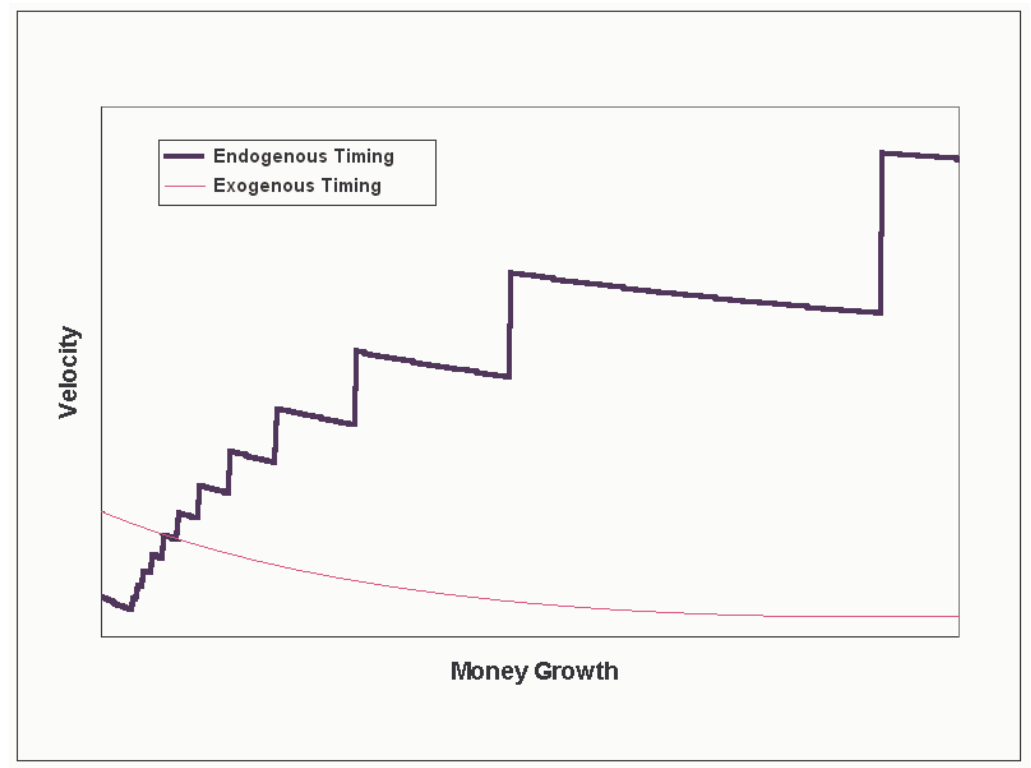

idea is that, the aggregate velocity is a weighted average of the individual velocities where the weights are given by the distribution of money holdings. With a higher money growth rate, a larger share of money is distributed to type $s=0$ who has a smaller individual velocity, thus lowering the aggregate velocity (Figure 5).

\subsection{Endogenous-Segmentation Model}

As discussed in section 3.2, with endogenous timing of money transfers, $N$ is decreasing in $\mu_{s s}$ because households choose to make transfers more frequently in response to a higher money growth. In the Appendix, it is shown that a reduction in $N$ can raise the velocity of money. Combining this result with proposition 1, we have the following finding.

Proposition 2: In an endogenous segmentation model with $\beta \rightarrow 1$ and $N>1$, as $\mu_{s s}$ increases, (1) $\bar{v}$ is decreasing when $N$ is fixed, and (2) $\bar{v}$ jumps up when $N$ is adjusted.

As shown in Figure 5, the relationship between velocity and money growth implied by the endogenous segmentation model is very different from that by the exogenous segmentation model. Which model can match the data better?

Now, I use the cross-country data to examine the correlation between money growth rate 
Figure 6: Velocity and Money Growth (OECD 1970-95)

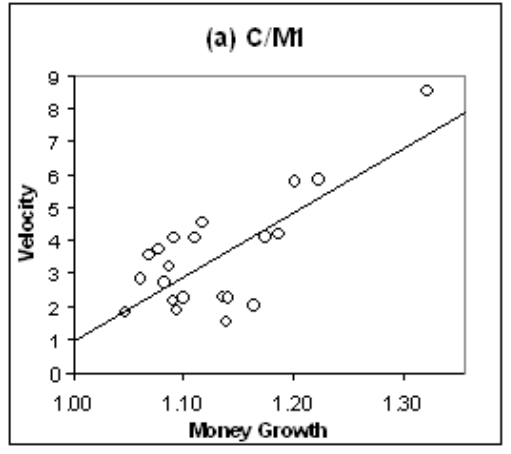

Correlation Coefficient $=\mathbf{0 . 7 4 4}(\mathrm{t}=\mathbf{4 . 8 5 3})$

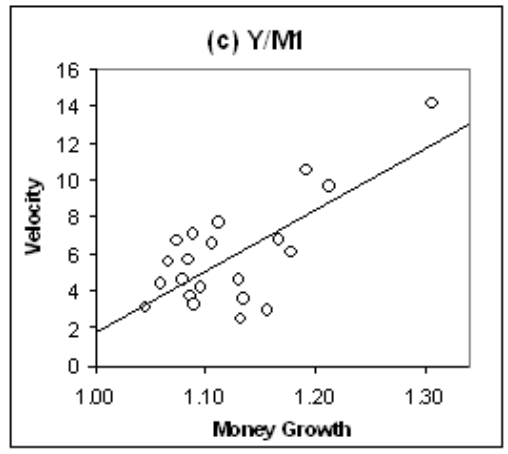

Correlation Coefficient $=0.720(t=4.518)$

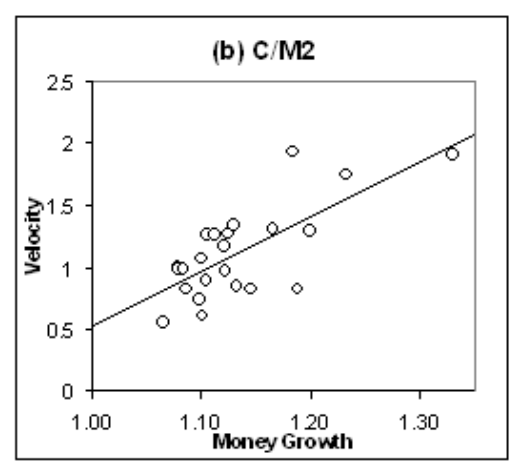

Correlation Coefficient $\mathbf{= 0 . 7 2 5}(\mathrm{t}=\mathbf{4 . 8 1 8})$

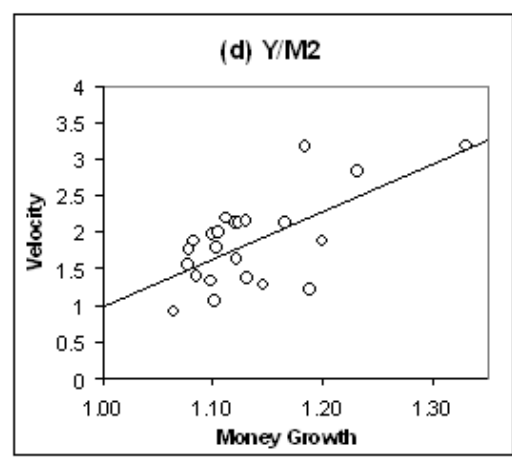

Correlation Coefficient $=0.653(t=3.950)$

and velocity. Using the IFS data of 23 OECD countries in 1970-1995, Figure 6 plots the (annual) income/consumption velocities of money measured in M1 and M2. The correlation coefficients between money growth rate and velocity are all significantly positive. Therefore, the implications of the endogenous segmentation model is more consistent with the long run relationship between money growth and the velocity of money exhibited by the cross-country data.

\section{Short Run Responses to Money Shocks}

In this section, I report results on the dynamic responses to money supply shocks. In Section 5.1 , I consider the exogenous segmentation model and derive the equilibrium effect of these shocks. This model displays special features such as a linear inflation response to shocks, liquidity effects, and sluggish price adjustment. Then, in Section 5.2, I consider the endogenous segmentation model, and use numerical examples to show that all these features are not robust. In particular, monetary effects are non-linear with respect to the size of money shocks. 


\subsection{Exogenous-Segmentation Model}

This section studies the short run effects of money supply shocks in an exogenous segmentation model. Suppose an economy is initially in a symmetric stationary equilibrium with $N$ types and the money growth rate is $\mu_{s s}=1$. In period 1 , there is a money growth shock $\Delta \mu_{1}$ brought about by an open market operation. I first outline how to derive the transitional path to simulate the effects of monetary shocks.

The transitional path can be solved by using the following steps ${ }^{11}$ :

(1) By using the money market equilibrium condition and the first order conditions of households, we can derive a set of equations expressing $P_{t}$ in terms of $P_{t-1}, \ldots, P_{t-N+1}$. Given the initial prices, the whole sequence of equilibrium commodity prices can then be solved iteratively.

(2) The goods market equilibrium condition and the first order conditions of households can be used to compute the sequence of equilibrium consumption of each type.

(3) The first order conditions of households pin down the $N$-period interest rates:

$$
\beta^{N} \prod_{j=1}^{N} R_{t+j-1}=\frac{P_{t+N-1}+\Delta M_{t+N}}{P_{t-1}+\Delta M_{t}}
$$

The price sequence can be substituted into these equations to yield the interest rates $R_{t}$ for $t \geq N$ in terms of $R_{1}, \ldots, R_{N-1}$.

(4) Finally, by substituting the prices, interest rates and consumption derived above into the life-time budget constraints of households, we can derive $N-1$ equations in $N-1$ unknowns $R_{1}, \ldots, R_{N-1}$.

Following these steps, we can numerically derive the dynamic responses to a permanent increase in the money growth rate $^{12}$. I set a period as a quarter $(\beta=0.9873)$ and suppose initially money grows at one percent per period $\left(\mu_{s s}=1.01\right)$. For simplicity and for easy comparison with Grossman and Weiss (1983) and Rotemberg (1984), I analyze as the benchmark the exogenous segmentation model with $N=2$. Suppose there is an unanticipated perma-

\footnotetext{
${ }^{11}$ Details are given in the Appendix.

${ }^{12}$ The effect of a temporary change in money growth is similar and is reported in the Appendix.
} 
nent money growth shock of size $\Delta \mu_{1}=0.25 \%$. Figure 7 illustrates the dynamic responses of price, velocity and interest rates to this money shock. The dynamic responses are derived in the Appendix. Here, we summarize the general features of these dynamic responses ${ }^{13}$.

(1) Sluggish price adjustment

The inflation rate in period one is lower than the size of the shock. The reason is that the new money received by households in the asset market is spent over the next two periods, and thus price level goes up gradually.

(2) Linear inflation response

In period one, the magnitude of price adjustment is proportional to the size of the money shock in the sense that the current inflation rate is a constant fraction of the money growth rate.

(3) Convergence to steady state with dampened oscillations

The price level oscillates around and converges to the new steady state price level.

(4) Liquidity effect

In period one, because only a fraction of households are present in the asset market, the interest rate has to drop to induce them to absorb all the money shock, leading to a liquidity effect $^{14}$.

(5) Interest Rate Cycle

The nominal interest rate $\left(R_{t}=\frac{1}{q_{t}}\right)$ oscillates around $\frac{\mu_{1}}{\beta}$ with lower rates in odd periods and higher rates in even periods, due to the persistent effect of wealth redistribution associated with open market operation.

(6) Variability of velocity

As discussed in Section 4, the money injection redistributes money holdings among households, resulting in the fluctuation of velocity.

\footnotetext{
${ }^{13}$ Exogenous segmentation models discussed in Grossman and Weiss(1983) and Alvarez, Atkeson and Edmond(2003) can generate similar implications.

${ }^{14}$ Note that there is real liquidity effect but not nominal liquidity effect in this case because the permanent money shock leads to an inflation expectation that drives up the nominal interest rate. There are nominal liquidity effects for less permanent money shocks.
} 

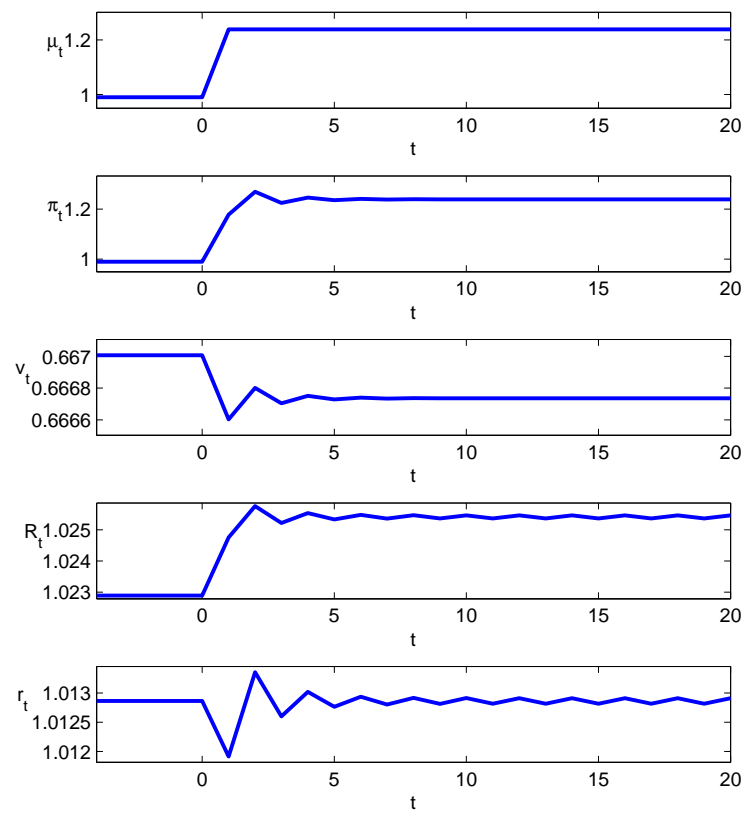

Figure 7: Response to 1\% Permanent Money Shock in Exogenous Segmentation Model $(N=$ 2)

\subsection{Endogenous-Segmentation Model}

In this section, I consider the effects of different monetary policies in an endogenous segmentation model. Subsection A derives how policy effects of small money shocks depend on the degree of asset market segmentation. Subsection B studies the effects of monetary shocks of different sizes by deriving the impact responses and transitional paths.

\section{[A]. Policy Effect and Degree of Asset Market Segmentation}

In the exogenous segmentation model, the response to money shocks depends on the degree of asset market segmentation when the shock hits the economy. In an endogenous segmentation model, this initial degree of market segmentation is determined by such fundamentals as longrun money growth rate and fixed cost. This section studies how the impact effects of small money shocks depend on these fundamentals. I focus on small shocks such that agents are not induced to adjust their transfer timing. A period is set as a quarter and pick $\beta=0.9873$. In this experiment, the long-run money growth $\left(\mu_{s s}\right)$ and fixed cost $(\eta)$ pin down the steady state degree of market segmentation. Suppose the economy is initially in steady state with $N$ types and is hit by a temporary injection of money. Figure 8 reports the degree of market segmentation $(N)$, the elasticities of inflation, interest rate and velocity with respect to money 
shocks for different combinations of $\mu_{s s}$ and $\eta$. The elasticities are evaluated at the steady state values.

Figure 8 shows that, for large $\mu_{s s}$ and small $\eta$, there is no asset market segmentation $(N=1)$. For example, look at the case when the money growth rate is 0.02 and the fixed cost is 0.01 . In this case, the elasticity of inflation is one and the elasticities of interest and velocity are zero: the price level is fully flexible and neither the interest rate nor the velocity respond to the shock.

For small $\mu_{s s}$ and large $\eta$, the asset market is segmented $(N>1)$. For example, look at the case when the money growth rate is 0 and the fixed cost is 0.2 . In this case, the elasticity of inflation is smaller than one and the elasticities of interest and velocity are negative: the price adjustment is sluggish and the interest rate and the velocity drop in response to a money injection.

In general, the elasticity of inflation is increasing in $\mu_{s s}$ and decreasing in $\eta$. In absolute terms, the elasticities of interest and velocity are decreasing in $\mu_{s s}$ and increasing in $\eta$. Therefore, an economy with lower long-run money growth and higher fixed cost should have higher degree of asset market segmentation, and thus with bigger liquidity effect, price sluggishness and reduction of velocity. ${ }^{15}$

\section{[B]. Policy Effect and Size of Money Shock}

In the last section, I study the policy effect for small shocks in economies with different initial degree of market segmentation. In this section, I fix the initial degree of market segmentation and study the effects of money shocks of different sizes. It is straightforward to show the following result (Proved in the Appendix.):

Proposition 3: In an endogenous segmentation model with $N>1$, for a sufficiently large money growth shock $\Delta \mu_{1}$ : (i) the equilibrium prices and allocation in an exogenous segmentation model cannot be supported as an equilibrium, and (ii) there exists an equilibrium with no liquidity effect and no sluggish price response.

\footnotetext{
${ }^{15}$ This is consistent with the finding in the cross country study of liquidity effects by Lastrapes and McMillin (2004). They find that the magnitude of the liquidity effect is decreasing in the degree of financial development.
} 
Figure 8: Monetary policy effect and asset market segmentation
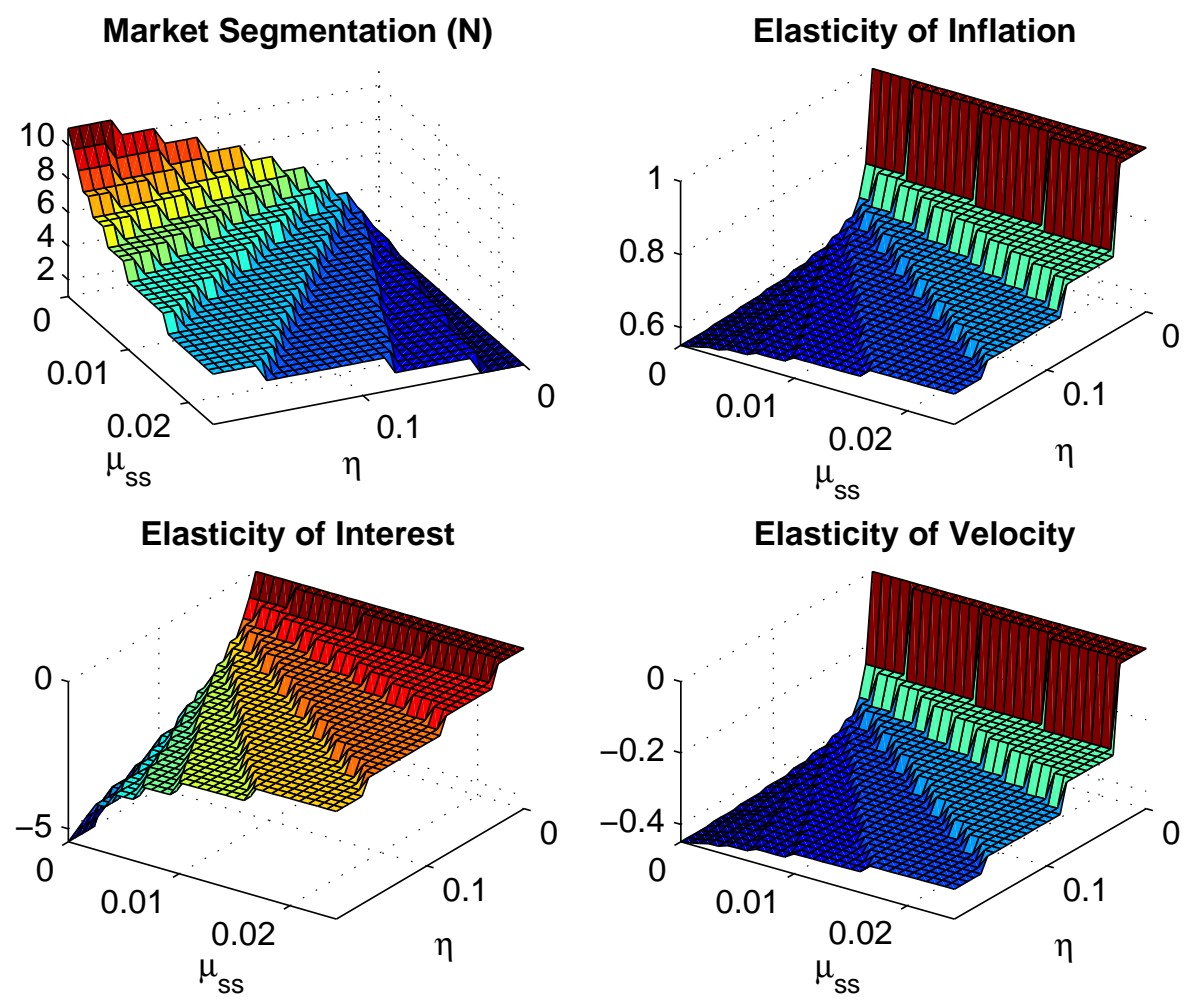

The idea is that for large $\Delta \mu_{1}$, the current real money balance of households absent from the asset market becomes so low that they are induced to pay the fixed cost and make money transfers, thus disturbing the equilibrium allocation in an exogenous segmentation model. Moreover, when all agents are induced to make money transfers, there is no asset market segmentation, and thus liquidity effect and sluggish price response vanish. Several numerical examples are provided below to highlight the non-linear response to money shocks of different sizes.

To illustrate the above idea, I consider a economy with $\beta=0.9873, \mu_{s s}=1.01, \eta=0.03$ (in an endogenous segmentation model) and $N=2$ (in an exogenous segmentation model). Suppose the (gross) money growth rate is raised permanently from $\mu_{s s}$ to $\mu_{s s}+\Delta \mu_{1}$ in period 1. To derive an equilibrium transitional path for each size of money shock $\Delta \mu_{1}$, I repeat the following steps:

(1) Conjecture households' timings of transfers.

(2) Aggregate household choices and compute the market clearing prices. 
(3) Given the prices, derive optimal choices of households.

Restart from (1) by updating the initial conjecture appropriately if needed.
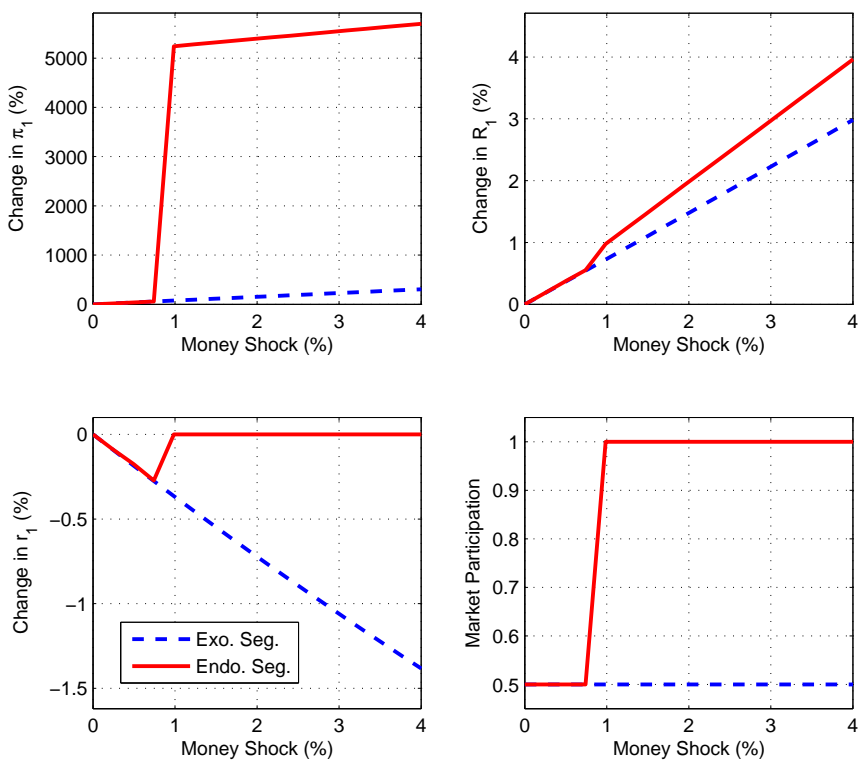

Figure 9: Response to Permanent Money Shocks in Period 1

Figure 9 plots the impact responses of interest rates, the inflation rate and the degree of market participation (the fraction of agents attending the asset market) to money shocks in period one. Unlike in the exogenous segmentation model, the responses to money shocks in an endogenous segmentation model can be non-linear and non-monotonic. For small shocks, an exogenous segmentation model is a good approximation of the endogenous segmentation model because the gain from adjusting transfer timings is small relative to the fixed cost. But for large shocks, implications of the exogenous segmentation model are not robust. As the money growth shock increases, more households choose to participate in the asset market in period one. As a result, the real interest rate goes up and the magnitude of the liquidity effect reduces. Moreover, since the money growth shock is permanent, households choose to increase the frequency of asset market participation. With a higher speed of money circulation, the inflation rate goes up. The rise in inflation expectation drives up the nominal interest rate. Finally, for $\Delta \mu_{1}>1 \%$, all households choose to attend the asset market every period. As a result, there is no liquidity effect or sluggish price response.

Figure 10 shows the responses to money shocks in period 1 for different sizes of the fixed cost $\eta$. As $\eta$ reduces, households have higher incentive to pay the fixed cost and transfer 

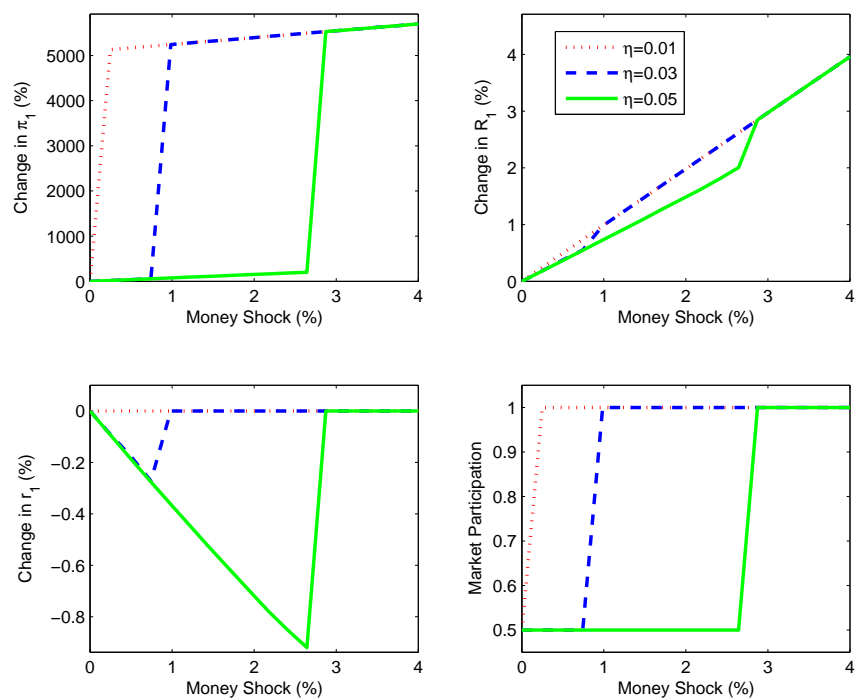

Figure 10: Response to Permanent Money Shocks for Different Fixed Costs in Period 1

money in the current period. As a result, for a given size of money shock, the interest rate, the inflation rate and the participation rate are (weakly) decreasing in $\eta$. Thus, in response to this type of shock, the implications of the exogenous segmentation model is less robust for smaller $\eta$.

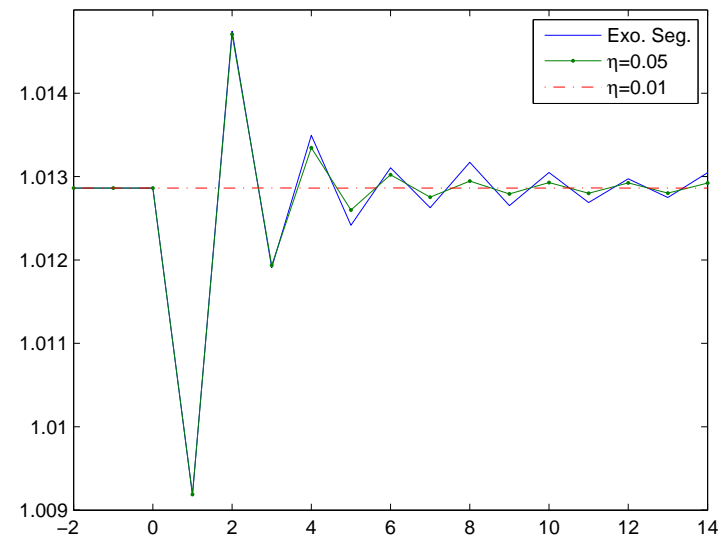

Figure 11: Response to 1\% Permanent Money Shocks

Figure 11 plots the dynamic responses of the real interest rate to a $1 \%$ money shock for different sizes of fixed cost. When the fixed cost is prohibitively high (as in the exogenous segmentation model), we have liquidity effect and persistent oscillation. When $\eta=0.05$, the induced participation dampens the interest rate oscillation. Finally, when $\eta=0.01$, all 
households are induced to participate every period, and thus the liquidity effect vanishes and the real interest rate is constant over time.
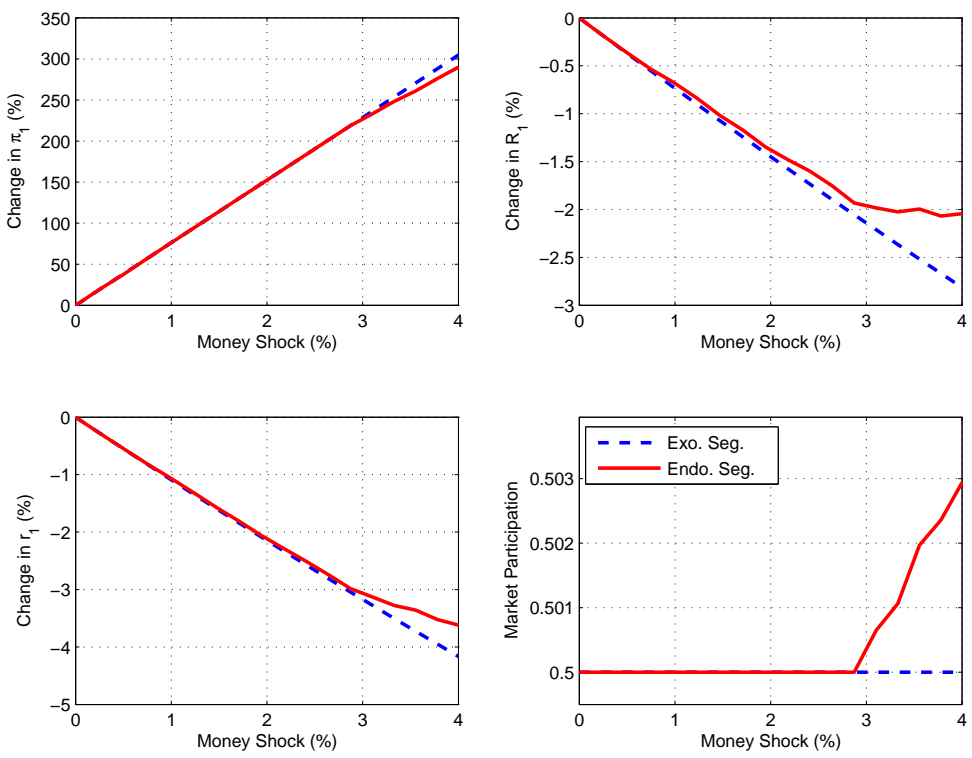

Figure 12: Response to Temporary Money Shocks in Period $1\left(\mu_{s s}=1.01, \beta=0.9873\right.$ and $\eta=0.025)$

Now, we study the effect of a temporary money growth shock. In period one, the (gross) money growth rate is raised temporarily from $\mu_{s s}$ to $\mu_{1}=\mu_{s s}+\Delta \mu_{1}$ and then it drops back to $\mu_{t}=\mu_{s s}$ for $t \geq 2$. Figure 12 reports the impact responses in period one for $\mu_{s s}=1.01$, $\beta=0.9873$ and $\eta=0.025$. For $\Delta \mu_{1}>3 \%$, more households are induced to participate in the asset market. As a result the nominal interest rate does not drop in response to further money injection and thus the liquidity effect is smaller than in an exogenous segmentation model. Since asset market participants tend to spend their money holdings slower than nonparticipants, a rise in participation rate implies a slower money circulation. As a result, the price response is even lower than in an exogenous segmentation model.

Again, the responses depends on the size of the shock. For a small shock (e.g. a one per cent shock in Figure 13), the participation rate does not change on impact and the magnitude of the liquidity effect is similar to that in an exogenous segmentation model. For a large shock (e.g. a four per cent shock in Figure 14), the participation rate goes up on impact and the liquidity effect is smaller than that in an exogenous segmentation model.

Figure 15 and Table 1 report the impact responses for both positive and negative (tem- 

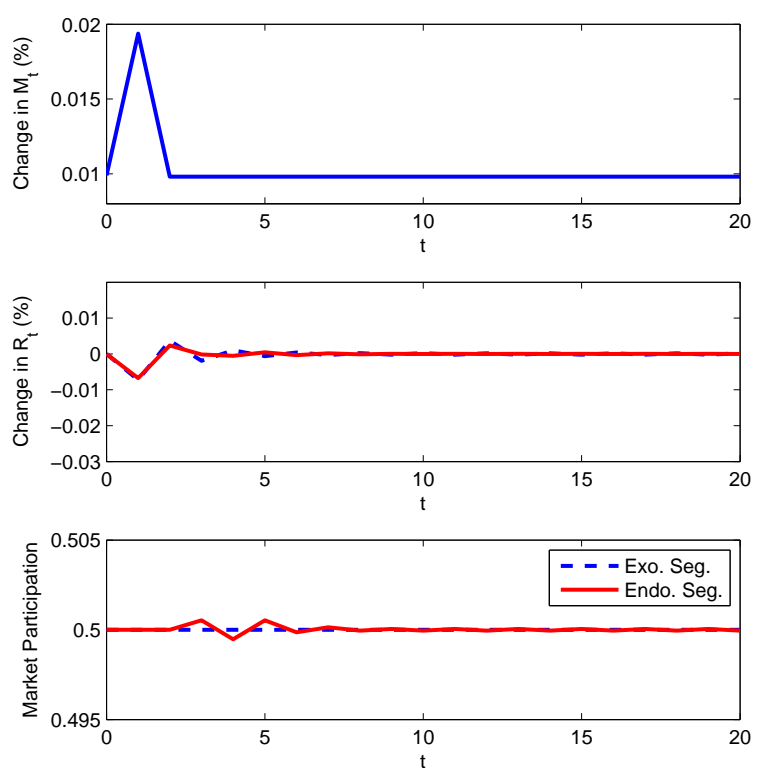

Figure 13: Response to 1\% Temporary Money Shocks
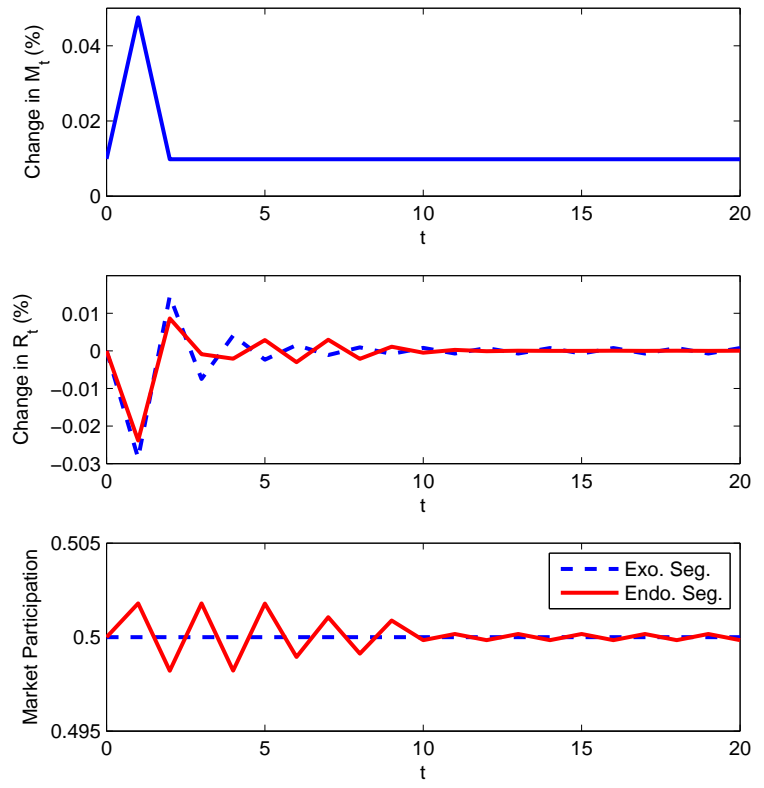

Figure 14: Response to 4\% Temporary Money Shocks 
Table 1: Response to temporary money shocks in period 1

\begin{tabular}{c|cccc}
\hline \hline$\Delta \mu_{1}$ & $\% \Delta \pi_{1}$ & $\% \Delta R_{1}$ & $\% \Delta r_{1}$ & $\% \Delta$ Part. \\
\hline$-4 \%$ & $-264 \%$ & $1.53 \%$ & $3.44 \%$ & $0 \%$ \\
$-2 \%$ & $-139 \%$ & $0.83 \%$ & $1.79 \%$ & $0 \%$ \\
$-1 \%$ & $-71 \%$ & $0.48 \%$ & $0.93 \%$ & $0 \%$ \\
\hline $0 \%$ & $0 \%$ & $0 \%$ & $0 \%$ & $0 \%$ \\
\hline $1 \%$ & $75 \%$ & $-0.67 \%$ & $-1.05 \%$ & $0 \%$ \\
$2 \%$ & $148 \%$ & $-1.35 \%$ & $-2.06 \%$ & $0 \%$ \\
$4 \%$ & $290 \%$ & $-2.04 \%$ & $-3.62 \%$ & $0.59 \%$ \\
\hline \hline
\end{tabular}

porary) money shocks. In an endogenous segmentation model, the responses are asymmetric to negative and positive shocks. It is in sharp contrast to an exogenous segmentation model in which the responses are always symmetric. First, the participation rate responds more to positive shocks than to negative shocks. To understand the intuition, we first note that households with zero balance in their checking accounts must participate in the asset market and thus the degree of market segmentation depends on whether the households with positive balance choose to pay the fixed cost to participate. To see the reason for this asymmetry, consider a stationary equilibrium in an exogenous segmentation model with $N=2$ and focus on the type of households who withdraws money only in even periods. In this stationary equilibrium, the Euler equation will imply that their odd period consumption is always lower than even period consumption because of discounting and (positive) inflation. Now, suppose in period one, these households are suddenly allowed to transfer money by paying a fixed cost. If the fixed cost is zero, they should choose to withdraw a positive amount to smooth the consumption profile. If the fixed cost is big, they will choose to not to transfer. Therefore, there is a tendency for them to withdraw a positive amount of money. Now, introducing the unanticipated money injection in period one, a positive injection will reinforce the withdrawal tendency and, if big enough, may outweigh the fixed cost. On the other hand, a negative injection can induce the agent to deposit money only if it is big enough to cancel out the combined effect of the fixed cost and that initial withdrawal tendency for consumption smoothing.

Second, price is more flexible in response to positive shocks than to negative shocks. Under a negative shock, the rise in nominal interest rate in period one induces (a fraction of) households to economize on their money holding by attending the asset market in both period one and two. This adjustment in transfer timing will speed up the money circulation and dampens the drop in price level. 

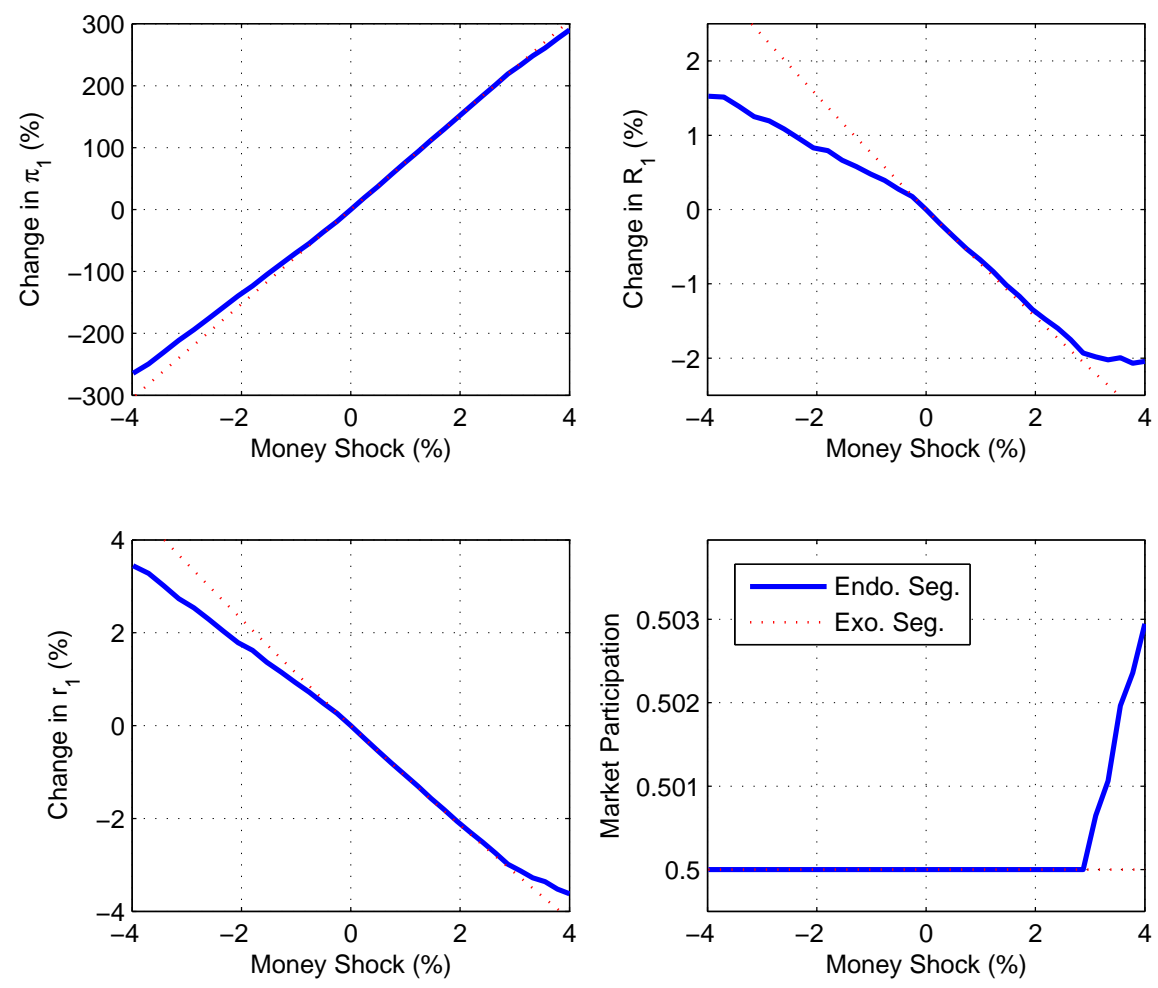

Figure 15: Asymmetric Response to Temporary Money Shocks in Period 1 


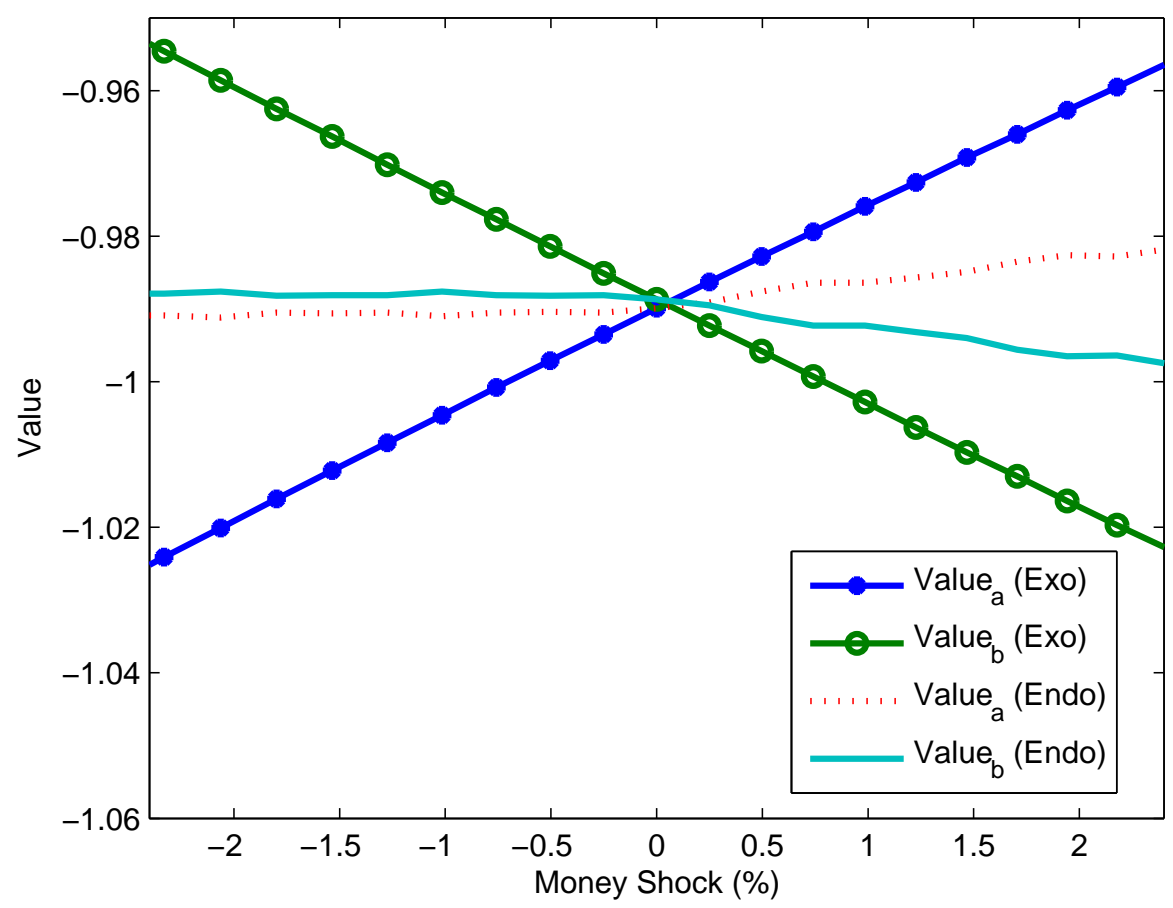

Figure 16: Welfare and Temporary Money Shocks

Finally, Figure 16 reports the effects of temporary money shocks on the welfare of the households. Denote the households with zero money holding at the beginning of period one as type $a$ (that is, $Z_{0}^{a}=0$ ) and denote the remaining households as type $b$ (that is, $Z_{0}^{b}>0$ ). The life-time discounted utilities evaluated in period 1 of the two types of households are plotted against the size of the money shock. A positive money shock redistribute wealth from money rich type $b$ households to money poor type $a$ households. As a result, type $a$ 's value is increasing in the size of the shock while type $b$ 's value is decreasing in it. The graph suggests that, by not allowing households to choose the optimal transfer timing, an exogenous segmentation model over-estimates the redistribution effect of a money shock.

\section{Conclusion}

I have developed a monetary model to endogenize agents' decision on money transfers between the asset market and the goods market by introducing a fixed transaction cost. By modeling the degree of market segmentation, this paper also endogenizes the magnitudes of liquidity effects, price sluggishness and variability of velocity. I show that the implications of an exogenous segmentation model are not robust in terms of the short run and long run effects of monetary policy. I show that the endogenous segmentation model can generate the positive 
long run relationship between money growth and velocity in the data which the exogenous segmentation model fails to capture. I also study the short run effects of unanticipated money shocks. First, in an exogenous segmentation model, responses to money shocks are linear, monotonic and symmetric. By contrast, in an endogenous segmentation model, responses are non-linear, non-monotonic and asymmetric. Second, an exogenous segmentation model is a good approximation of the endogenous segmentation model only for small money shocks. For large money shocks, implications of the exogenous segmentation model are not robust. In particular, for large persistent shocks, there is no liquidity effect and no sluggish price response in an endogenous segmentation model. 


\section{References}

[28] Alvarez, Fernando, Andrew Atkeson and Patrick J. Kehoe.(1999). Money and Interest Rates with Endogeneously Segmented Markets, NBER Working Paper No. w7060.

[28] Alvarez, Fernando, Andrew Atkeson and Chris Edmond. (2003). On the Sluggish Response of Prices to Money in an Inventory-Theoretic Model of Money Demand, NBER Working Paper No. w10016.

[28] Baumol, William J. (1952). The Transactions Demand for Cash: An Inventory Theoretic Approach, Quarterly Journal of Economics. 66(4): 545-56.

[28] Chatterjee, Satyajit, and Dean Corbae. (1992). Endogenous Market Participation and the General Equilibrium Value of Money, Journal of Political Economy, 100 (no. 3, June), 61546 .

[28] Christiano, L. (1991), Modeling the Liquidity Effect of a Money Shock, Federal Reserve Bank of Minneapolis Quarterly Review Vol. 15 No. 1, Winter 1991.

[28] Christiano L., Eichenbaum M. and C. Evans (1995), Liquidity Effects, Monetary Policy, and the Business Cycle, Journal of Money, Credit and Banking, Vol. 27, No. 4, Part 1,(Nov., 1995), pp. 1113-1136.

[28] Christiano L., Eichenbaum M. and C. Evans (1997), Sticky Price and Limited Participation Models of Money: A Comparison, European Economic Review, Vol. 41(6), pages 1201-1249.

[28] Christiano L., Eichenbaum M. and C. Evans (2001), Nominal Rigidities and the dynamic effects of shocks to monetary policy, working paper.

[28] Cochrane, John H. (1989), The Return of the Liquidity Effect: A Study of the Short-run Relation between Money Growth and Interest Rates, Journal of Business and Economic Statistics 7(January 1989), 75-83.

[28] Dotsey, Michael and Robert G. King (2001), Pricing, Production and Persistence, NBER Working Paper No. w8407.

[28] Edge, Rochelle M. (2000), Time-to-Build, Time-to-Plan, Habit-Persistence, and the Liquidity Effect, International Finance Working Paper No. 673.

[28] Edmond, Chris. (2003). Sticky Demand vs. Sticky Prices, manuscript. 
[28] Grauwe, Paul De and Magdalena Polan. (2001). Is inflation always and everywhere a monetary phenomenon? Discussion Paper No. 2841 Center for Economic Policy Research.

[28] Gordon, David B. and Eric M. Leeper (1994), The Dynamic Impacts of Monetary Policy: An Exercise in Tentative Identification, The Journal of Political Economy, Vol. 102, No. 6. Dec., pp. 1228-1247.

[28] Grossman, Sanford J. Monetary Dynamics With Proportional Transaction Costs and Fixed Payment Periods. In New Approaches to Monetary Economics: Proceedings of the Second International Symposium in Economic Theory and Econometrics, edited by William A. Barnett and Kenneth J. Singleton. Cambridge, U.K.: Cambridge University Press, 1987.

[28] Grossman, Sanford J, and Weiss, Laurence. (1983). A Transactions-Based Model of the Monetary Transmission Mechanism, American Economic Review. 73(5): 871-80.

[28] Hamilton, James D, 1997. "Measuring the Liquidity Effect," American Economic Review, American Economic Association, vol. 87(1), pages 80-97, March.

[28] Hodrick, R.J., Kocherlakota, N. and D. Lucas, 1991, The Variability of Velocity in Cash-in- Advance Models, Journal of Political Economy 99: 358-384.

[28] Jovanovic, Boyan (1982), Inflation and Welfare in the Steady State, The Journal of Political Economy, Volume 90, Issue (Jun., 1982), 561-577.

[28] Keen, Benjamin (2001), In Search of the Liquidity Effect in a Modern Monetary Model, manuscript.

[28] Khan, Aubhik and Julia K. Thomas (2006), Inflation and Interest Rates with Endogenous Market Segmentation, Federal Reserve Bank of Philadelphia working paper.

[28] Rodríguez Mendizábal, Hugo (2004), The Behavior of Money Velocity in Low and High Inflation Countries, Universitat Autonoma de Barcelona and centrA, Working Paper.

[28] Romer, David. (1986). A Simple General Equilibrium Version of the BaumolTobinModel, Quarterly Journal of Economics 101 (no. 4, November): 66385.

[28] Rotemberg, Julio J. (1984). A Monetary Equilibrium Model with Transactions Costs, Journal of Political Economy. 92(1): 40-58. 
[28] Strongin, Steven (2000), The identification of monetary policy disturbances explaining the liquidity puzzle, Journal of Monetary Economics Volume 35, Issue 3, June 1995, Pages 463-497.

[28] Tobin, James. (1956). The Interest-Elasticity of the Transactions Demand for Cash, Review of Economics and Statistics. 38(3): 241-247.

[28] Vissing-Joregensen, Annette (2002). Towards an Explanation of Household Portfolio Choice Heterogeneity: Nonfinancial Income and Participation Cost Structures, Manuscript, University of Chicago.

[28] Wang, Weimin and Shouyong Shi (2001), The Variability of the Velocity of Money in a Search Model, manuscript. 


\section{APPENDIX}

\section{A. Derivation of Stationary Equilibrium in Exogenous Segmentation Models}

Let $\gamma_{t}(s)$ and $\lambda_{t}(s)$ respectively denote the Lagrange multipliers for the constraints (3) and (4) of a type $s$ household. Let $\delta_{t}(s)$ denote the multipliers on the non-negativity constraints for $Z_{t}(s)$ of a type $(s)$ household. The first order necessary conditions for the optimization problem include

$$
\begin{aligned}
& x_{t} \quad: \quad \gamma_{t}(0)=\lambda_{t}(0) \\
& c_{t}(s): \gamma_{t}(s)=\beta^{t}\left(P_{t} c_{t}(s)\right)^{-1} \\
& B_{t}(s): q_{t} \lambda_{t}(s)=\lambda_{t+1}(s+1) \\
& Z_{t}(s): \delta_{t}(s)+\gamma_{t+1}(s+1)=\gamma_{t}(s)
\end{aligned}
$$

I focus on equilibria in which two conditions are satisfied. The first condition is that the nominal interest rate $R_{t}-1=\frac{1}{q_{t}}-1$ is positive, implying no households will hold money in the brokerage accounts. The second condition is that $c_{t+1}(0) P_{t+1}>\beta c_{t}(N-1) P_{t}$ for all $t$, implying $Z_{t}(N-1)=0$ for all $t$. Under these assumptions, in a stationary equilibrium, the first order conditions and budget constraints imply (5) and (6). The goods market and the money market equilibrium conditions imply (7) and (8).

B. To prove: When $p_{t}=p$ and $q_{t}=q=\frac{\beta}{\mu_{s s}}, t_{j+1}^{*}-t_{j}^{*}=n$ for $j=1,2, \ldots$ and for some positive integer $n$.

Proof: For a given choice of $d$, the first order conditions with respect to $\left\{c_{t}\right\}_{t=0}^{\infty}$ imply $c_{t_{j}}=c_{0}$ for $j=1,2, \ldots$ and $c_{t_{j}+k}=\left(\frac{\beta}{\mu_{s s}}\right)^{k} c_{t_{j}}$ for $j=1,2, \ldots$ and $k<t_{j+1}-t_{j}$. Denoting the initial wealth by $w_{-1}=\frac{b_{-1}+p\left(1-\tau \mu_{s s}\right) /(1-\beta)}{\mu_{s s}}$, we can solve for the optimal consumption in period $t$ associated with $d$ as a fraction of the initial wealth: $c_{t}(d)=f_{t}(d) w_{-1}$. As a result, the payoff associated with $d$ is $U(d)=\sum_{t=0}^{\infty} \beta^{t}\left[\ln \left(c_{t}(d)\right)-J(d) \eta\right]=\frac{\ln w_{-1}}{1-\beta}+\sum_{t=0}^{\infty} \beta^{t}\left[\ln \left(f_{t}(d)\right)-J(d) \eta\right]$, implying that the optimal choice of $d$ is independent of the initial wealth. Therefore, if the optimal date of the first transfer is $t_{1}$, then the optimal date of the $i$ th transfer is $t_{i}=i \times t_{1}$ for $i=1,2, \ldots$

\section{Derivation of $G(n)$ and $D(n)$}

Denote the value of transferring every $n$ periods by $V(n)$. We can show that

$$
\begin{aligned}
V\left(n ; b_{-1}, p\right) & =\left[\sum_{s=0}^{n-1} \beta^{s} \ln \left(c_{s}\right)-\eta\right] /\left(1-\beta^{n}\right) \\
& =\sum_{s=0}^{n-1} \beta^{s} \ln f_{s} /\left(1-\beta^{n}\right)-\eta /\left(1-\beta^{n}\right)+\ln \left(1-\beta^{n}\right) /(1-\beta)+\Delta_{0}
\end{aligned}
$$


where $f_{s}=\frac{\beta^{s} / \mu_{s s}^{s}}{1+\beta+\ldots+\beta^{n-1}}$ and $\Delta_{0}=\ln \left[\frac{b_{-1}+p\left(1-\tau \mu_{s s}\right) /(1-\beta)}{p \mu_{s s}}\right] /(1-\beta)$. Differentiate $V$ with respect to $n$,

$$
V^{\prime}(n)=\frac{\beta^{n}(1-\beta)}{(1-\beta)^{2}\left(1-\beta^{n}\right)^{2}}\left[-\eta(1-\beta) \ln \beta-\ln \left(\frac{\beta}{\mu_{s s}}\right)\left\{1-\beta^{n}+n \ln \beta\right\}\right]
$$

Therefore, $\operatorname{sign}\left(V^{\prime}(n)\right)=\operatorname{sign}(G(n)-D(n))$.

D. To prove: For each set of $\left(\eta, \beta, \mu_{s s}, \tau\right)$, a SSE exists. Generically, this is the unique SSE.

Proof: First, $(C 1)$ implies that the optimal choice of $n$ is independent of initial bond holding and price level, thus households' choices of $n$ are independent. Given $n^{*}$, we can use the formulae in section 3.1 to derive the symmetric stationary equilibrium. To see why the equilibrium is generically unique, first note that there exists at most two equilibria which happens when agents are indifferent between $\underline{n}$ and $\underline{n}+1$, that is $V(\underline{n}+1 ; \eta)=V(\underline{n} ; \eta)$. In this case, we can raise the fixed cost to $\eta^{\prime}=\eta+\varepsilon$ with $\varepsilon>0$. If $\varepsilon$ is sufficiently small, then $n^{*}$ is still equal to $\underline{n}$ or $\underline{n}+1$. As a result, the unique optimal choice becomes $\underline{n}+1$ because $V\left(\underline{n}+1 ; \eta^{\prime}\right)>V\left(\underline{n} ; \eta^{\prime}\right)$.

E. Proposition (1): In an exogenous segmentation model, if $N>1$, as $\beta \rightarrow 1, \bar{v}$ is decreasing in $\mu_{s s}$.

$$
\begin{aligned}
& \text { Proof: } \frac{d \bar{v}}{d \mu_{s s}}=\frac{d}{d \mu_{s s}}\left(\left[\sum_{s=0}^{N-1} \frac{N-s}{\mu_{s s}^{s}}\right]^{-1} \frac{\mu_{s s}^{N}-1}{\mu_{s s}^{N-1}\left(\mu_{s s}-1\right)}\right) \\
= & \frac{d}{d \mu_{s s}}\left[\mu_{s s}^{N} N-\mu_{s s}^{N-1}-\mu_{s s}^{N-2}-\ldots-\mu_{s s}-1\right]^{-1}\left(\mu_{s s}^{N}-1\right) \\
= & -\left[\left[\frac{1+\mu_{s s}+\ldots+\mu_{s s}^{N-1}}{N}\right]^{2}-\mu_{s s}^{N-1}\right] \Delta_{1} \\
\leq & {\left[\mu_{s s}^{N-1}-\mu_{s s}^{N-1}\right] \Delta_{1}=0, }
\end{aligned}
$$

where $\Delta_{1}$ is a positive term. And the last step is implied by the Jensen's inequality because the term $\frac{1+\mu_{s s}+\ldots+\mu_{s s}^{N-1}}{N}>\mu_{s s}^{\frac{N-1}{2}}$ if $\mu_{s s} \neq 1\left(=\mu_{s s}^{\frac{N-1}{2}}\right.$ if $\left.\mu_{s s}=1\right)$

\section{F. Velocity is decreasing in $N$ as $\beta \rightarrow 1$}

Proof: For $\beta \rightarrow 1$, velocity is given by

$$
\bar{v}=\left[\sum_{s=0}^{N-1} \frac{N-s}{\mu_{s s}^{s}}\right]^{-1} \frac{\mu_{s s}^{N}-1}{\mu_{s s}^{N-1}\left(\mu_{s s}-1\right)}=\frac{1}{\frac{\mu_{s s}}{1-\mu_{s s}}+\frac{N \mu_{s s}^{N}}{\mu_{s s}^{N}-1}},
$$

and $\frac{d \bar{v}}{d N} \leq 0$ if $\left[\mu_{s s}^{N}-1-N \ln \mu_{s s}\right] \geq 0$. It can be shown that $\mu_{s s}^{N}-1-N \ln \mu_{s s}>0$ for $\mu_{s s} \neq 1$ and $\mu_{s s}^{N}-1-N \ln \mu_{s s}=0$ for $\mu_{s s}=1$. 


\section{G. Derivation of Transitional Path in an exogenous segmentation Model with $N$ types}

For simplicity, here assumes zero money growth in the steady state and derives the effects of a permanent increase in money stock. It is straightforward to extend to other cases. To find the transitional path, we make use of the following conditions:

(1) Life-time budget constraint: the type 0 in period 1 faces

$$
\sum_{t=1, N+1,2 N+1, \ldots} \frac{N\left(P_{t-1}+\Delta M_{t}\right)}{\prod_{j=1}^{t-1} R_{j}} \leq W_{0}(0)
$$

with

$$
W_{0}(0)=\sum_{t=0}^{\infty} \frac{P_{t}}{\prod_{j=1}^{t-1} R_{j}}+B_{0}(0)-\overline{B_{0}}+\sum_{t=1}^{\infty} \frac{\Delta M_{t}}{\prod_{j=1}^{t-1} R_{j}}
$$

similar constraints apply to type $1, \ldots, N-1$.

(2) Market clearing conditions:

Goods:

$$
\sum_{i=0}^{N-1} \frac{1}{N} c_{t}(i)=1, \text { all } t
$$

Money:

$$
\sum_{i=0}^{N-1} \frac{1}{N} M_{t}(i)=M_{t}, \text { all } t
$$

(3) Optimal Consumption:

Let $\phi_{i}=\beta^{i-1} / \sum_{j=1}^{N} \beta^{j-1}$ and $\Phi_{i}=\sum_{j=i}^{N} \phi_{j}$, for $i=1, \ldots, N$, optimal choice of consumption implies, for $t=1, N+1,2 N+1, \ldots$ :

$$
c_{t+j}(0)=N \phi_{j+1} \frac{\left(P_{t-1}+\Delta M_{t}\right)}{P_{t+j}}, \text { for } j=0, \ldots, N-1
$$


similar conditions for type $1, \ldots, N-1$.

(4) Equilibrium Price Sequence:

Money market clearing condition implies

$$
\begin{aligned}
P_{0}= & M_{0}-\frac{1}{N} \sum_{j=1}^{N-1} \frac{\Phi_{j+1}}{\Phi_{j}} M_{0}(j-1) \\
P_{1}= & M_{1}-\Phi_{2}\left(P_{0}+\Delta M_{1}\right)-\frac{1}{N} \sum_{j=1}^{N-2} \frac{\Phi_{j+2}}{\Phi_{j}} M_{0}(j-1) \\
P_{2}= & M_{1}-\Phi_{3}\left(P_{0}+\Delta M_{1}\right)-\Phi_{2} P_{1}-\frac{1}{N} \sum_{j=1}^{N-3} \frac{\Phi_{j+3}}{\Phi_{j}} M_{0}(j-1) \\
& \vdots \\
P_{N-1}= & M_{1}-\Phi_{N}\left(P_{0}+\Delta M_{1}\right)-\sum_{j=2}^{N-1} \Phi_{j} P_{N-j} \\
P_{t}= & M_{1}-\sum_{j=2}^{N} \Phi_{j} P_{t-j+1}, \text { for } t \geq N
\end{aligned}
$$

(5) Equilibrium Interest Rate Sequence:

$$
\prod_{j=1}^{N} R_{j}=\beta^{-N} \frac{P_{N}}{P_{0}+\Delta M_{1}}
$$

For $t \geq 2$,

$$
\prod_{j=1}^{N} R_{t+j-1}=\beta^{-N} \frac{P_{t+N-1}}{P_{t-1}}
$$

First, we can solve for the steady state:

(i) $P=M / \sum_{j=i}^{N} \Phi_{j}$

(ii) $M(0)=N P, M(j)=\Phi_{j} M(0)$ for $j=1, \ldots, N-1$

(iii) $R=\frac{1}{\beta}$ 
(iv) $c^{j}=\phi_{j} M(0) / P$

(v) $B_{0}(0)=\overline{B_{0}}+P\left[\frac{N}{1-\beta^{N}}-\frac{1}{1-\beta}\right]$, and $B_{0}(j)=\overline{B_{0}}+P\left[\frac{N \beta^{N-j}}{1-\beta^{N}}-\frac{1}{1-\beta}\right]$ for $j=1, \ldots, N-1$.

To derive the transitional path, I first use (4) to compute the prices, then use (2) and (3) to compute the consumption sequence. (1) can then imply the initial $N-1$ interest rates $\left(R_{1}, \ldots, R_{N-1}\right)$. By equating the lifetime expenditure and wealth, one can get, for $j=1, \ldots, N-1$ :

$R_{j}=\left[\frac{\left(\Theta+B_{0}^{j+1}-B_{0}\right) \prod_{k=1}^{j-1} R_{k}\left(1-\beta^{N}\right)}{N P_{j}}\right]^{-1}$

where $\Theta=\left(P_{0}+\Delta M_{1}\right) \frac{1}{1-\beta^{N}}+\overline{B_{0}}-B_{0}(0)$

Lastly, (5) can be used to derive the whole interest rate sequence.

H. Properties of dynamic response in exogenous segmentation model for $N=2$

(i) Derivation of $R_{1}$

First, the life-time expenditure of a type $a$ is $\operatorname{Exp}_{0}^{a}=P_{1} c_{1}^{a}+2\left(\Delta M_{1}+P_{0}\right) /\left(1-\beta^{2}\right)$. And the life-time wealth is $W_{0}^{a}=Z_{0}^{a}+\frac{P_{0}}{1+\beta}+\frac{P_{0}+\mu-1}{1-\beta^{2}}+\frac{P_{1}+\mu(\mu-1)}{\left(1-\beta^{2}\right) R_{1}}$. Solving for the $R_{1}$ that equates $\operatorname{Exp}_{0}^{a}$ and $W_{0}^{a}$ gives $R_{1}=\frac{P_{1}+\Delta M_{2}}{\Delta M_{1}+\beta P_{0}}$.

(ii) $P_{1}<P_{0} \mu$

Because $P_{0}=\frac{1+\beta}{1+2 \beta}$ and $P_{1}=\frac{1+\beta}{1+2 \beta}+\frac{\mu-1}{1+\beta}$, we have $P_{0} \mu>P_{1}$ if $\beta^{2}>0$.

(iii) $\frac{P_{1}-P_{0}}{P_{0}}=(\mu-1) k$ for constant $k$

$\frac{P_{1}-P_{0}}{P_{0}}=\left(\frac{\mu-1}{1+\beta}\right) /\left(\frac{1+\beta}{1+2 \beta}\right)=(\mu-1) \frac{1+2 \beta}{(1+\beta)^{2}}$

(iv) $R_{1}<P_{2} /\left(P_{1} \beta\right)$

Real interest rate is smaller than $\beta^{-1}$ if $\frac{P_{1}+\Delta M_{2}}{\Delta M_{1}+\beta P_{0}}<P_{2} /\left(P_{1} \beta\right)$. This is true because $\mu(1-$ $\beta)(\mu-1)+\beta\left(\mu P_{0}-P_{1}\right)>0$.

(v) $P_{t} / P_{t-1} \rightarrow \mu$

Solving the set of equations in terms of price level, we get

$$
P_{t}=(-\phi)^{t-1} P_{1}+\sum_{j=1}^{t-1}(-\phi)^{t-1-j}\left[(1-\phi) M_{j+1}+\phi M_{j}\right]
$$

Therefore, $\mu P_{t-1}-P_{t}=\mu(-\phi)^{t-2} P_{1}-(-\phi)^{t-1} P_{1}-(-\phi)^{t-2}\left[(1-\phi) M_{2}+\phi M_{1}\right] \rightarrow 0$ as $\phi<1$.

(vi) Interest rate Cycles

For $t=2,4, \ldots, R_{t}=\frac{\Delta M_{1}+\beta P_{0}}{\Delta M_{1}+P_{0}} \frac{1}{\beta^{2}} \frac{\Delta M_{t+1}+P_{t}}{\Delta M_{t}+P_{t-1}}$ For $t=3,5, \ldots, R_{t}=\frac{\Delta M_{1}+P_{0}}{\Delta M_{1}+\beta P_{0}} \frac{\Delta M_{t+1}+P_{t}}{\Delta M_{t}+P_{t-1}}$ 
As $t \rightarrow \infty, R_{\text {even }}>R_{\text {odd }}$ if $(\mu-1)^{2}\left(1-\beta^{2}\right)+2 \beta P_{0}(\mu-1)(1-\beta)>0$.

\section{Linear Inflation Response in Period 1 in a Exogenous segmentation Model}

Proof: Consider an exogenous segmentation model with $N$ types:

$$
\begin{aligned}
P_{1} & =M_{1}-\Phi_{2}\left(P_{0}+\Delta M_{1}\right)-\frac{1}{N} \sum_{j=1}^{N-2} \frac{\Phi_{j+2}}{\Phi_{j}} M_{0}(j-1) \\
& =\mu-\frac{\sum_{j=1}^{N-1} \beta^{j}}{\sum_{j=1}^{N} \beta^{j-1}}\left[\frac{\sum_{j=1}^{N} \beta^{j-1}}{\sum_{j=1}^{N} j \beta^{j-1}}-(\mu-1)\right]-\frac{\sum_{j=1}^{N-2} j \beta^{1+j}}{\sum_{j=1}^{N} j \beta^{j-1}} \\
& =\mu-\frac{\sum_{j=1}^{N-1} j \beta^{j}}{\sum_{j=1}^{N} j \beta^{j-1}}-\frac{\sum_{j=1}^{N-1} \beta^{j}}{\sum_{j=1}^{N} \beta^{j-1}}(\mu-1)
\end{aligned}
$$

Change in price is $P_{1}-P_{0}=\frac{\mu-1}{\sum_{j=1}^{N} \beta^{j-1}}$ and the inflation rate in period one is

$$
\frac{P_{1}-P_{0}}{P_{0}}=\frac{\sum_{j=1}^{N} j \beta^{j-1}}{\left(\sum_{j=1}^{N} \beta^{j-1}\right)^{2}}(\mu-1)
$$

\section{J. Dynamic responses to a temporary money growth shock in Exogenous seg- mentation $\operatorname{Model}(N=2)$}

Suppose initially there is no money growth $\left(\mu_{s s}=1\right)$ and $\beta=0.96$, The dynamic responses to a temporary money growth shock $\Delta \mu=0.1 \%$ is as follows:

\section{K. Proof of proposition 3.}

Proof: Start with the equilibrium prices and allocations in an exogenous segmentation model equilibrium with $N$ types. Define the nominal wealth (excluding money holding) of a type $N-1$ in period one as $W_{0}$ and the nominal money holding as $Z_{0}$. In this equilibrium, this household receives utility $V_{1}\left(Z_{0}, W_{0}\right)=\log \left(c_{1}\right)+\sum_{k=0}^{\infty} \beta^{t-1}\left[\sum_{j=0}^{N-1} \beta^{j} \log \left(c_{2+k N+j}\right)-\eta\right]$ where

$$
\begin{aligned}
c_{1} & =Z_{0} / P_{1}, \\
c_{2} & =W_{0} R_{1}(1-\beta) / P_{2}, \\
c_{2+k N+i} & =\beta^{k N+i} \prod_{j=0}^{k N-1} R_{2+j} P_{2} c_{2} / P_{2+k N+i}, \\
\text { for } k & =0,1,2, \ldots \text { and } i=0, \ldots, N-1
\end{aligned}
$$



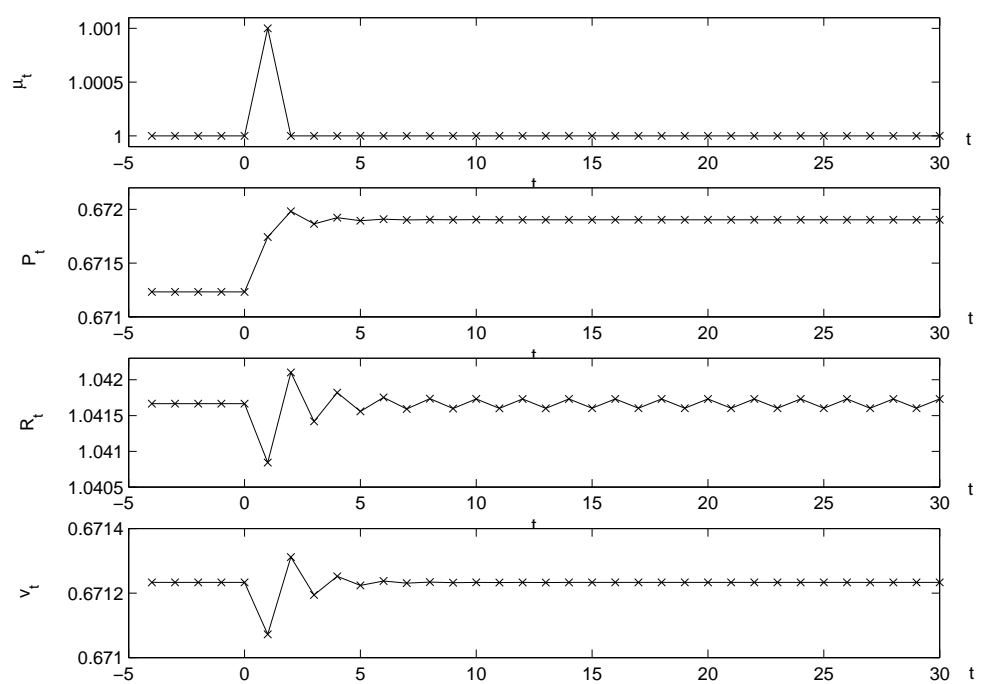

Figure 1: Response to $0.1 \%$ Temporary Money Growth Shock in exogenous segmentation Model $(N=2)$

To disturb the above equilibrium, consider an alternative choice where type $b$ transfers also in period one. The value is $V_{2}\left(Z_{0}, W_{0}\right)=\log \left(c_{1}^{\prime}\right)-\eta+\sum_{k=0}^{\infty} \beta^{t-1}\left[\sum_{j=0}^{N-1} \beta^{j} \log \left(c_{2+k N+j}^{\prime}\right)-\eta\right]$

$$
\begin{aligned}
c_{1}^{\prime} & =\left(Z_{0}+W_{0}\right)(1-\beta) / P_{1}, \\
c_{2}^{\prime} & =R_{1} \beta P_{1} c_{1}^{\prime} / P_{2}, \\
c_{2+k N+i}^{\prime} & =\beta^{k N+i} \prod_{j=0}^{k N-1} R_{2+j} P_{2} c_{2}^{\prime} / P_{2+k N+i}, \\
\text { for } k & =0,1,2, \ldots \text { and } i=0, \ldots, N-1
\end{aligned}
$$

It can be shown that the gain from transferring in period one is $V_{2}\left(Z_{0}, W_{0}\right)-V_{1}\left(Z_{0}, W_{0}\right)=$ $\log \left(Z_{0}+W_{0}\right)-\Delta_{2}$ where $\Delta_{2}$ is a positive constant. The gain is positive for large $\mu$ because $W_{0}$ goes to infinity as $\mu$ increases.

(ii) To prove that it is optimal for a household with $Z_{0}(i)=0$ to transfer every period, we need to show $G(1)<D(1)$. This is true for large $\mu$. To prove that it is optimal for a household with $Z_{0}(i)>0$ to transfer every period, I first define the real money balance in period one as $m=Z_{0}(i) / P_{1}$ and the real wealth (excluding $m$ ) in period one as $w=W_{0}(i) / P_{1}$, where $W_{0}(i)=P_{0}+\frac{\beta}{1-\beta}+B_{0}(i)-\bar{B}_{0}+\frac{\mu-1}{1-\beta}$. Also, by assuming a household will exhaust money holding before any transfer, I define the value of making the first transfer in period $T$ as $V_{T}(m, w)$. It can be shown that $V_{1}(m, w)>V_{T}(m, w)$ for all $T>1$ if $\log \left[W_{0}(i)+Z_{0}(i)\right]>\Delta_{3}$ (where $\Delta_{3}$ is a positive constant) which is true for large $\mu$. Finally, the condition for type $b$ to exhaust money holding before making transfer in period $T$ is $\left(1-\beta^{T-1}\right) w \frac{\mu^{T}}{\beta^{2(T-1)}}>Z_{0}(i)$ which is true for large $\mu$. 